\title{
Air-snow transfer of nitrate on the East Antarctic Plateau - Part 1: Isotopic evidence for a photolytically driven dynamic equilibrium in
} summer

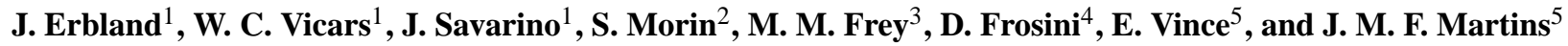 \\ ${ }^{1}$ UJF-Grenoble 1/CNRS, LGGE UMR5183, Grenoble, France \\ ${ }^{2}$ Météo-France - CNRS, CNRM - GAME URA1357, CEN, Grenoble, France \\ ${ }^{3}$ British Antarctic Survey, Natural Environment Research Council, Cambridge, UK \\ ${ }^{4}$ Department of Chemistry, University of Florence, Sesto Fiorentino, Italy \\ ${ }^{5}$ UJF-Grenoble 1/CNRS-INSU/G-INP/IRD, LTHE UMR5564, Grenoble, France
}

Correspondence to: J. Erbland (joseph.erbland@ujf-grenoble.fr)

Received: 29 August 2012 - Published in Atmos. Chem. Phys. Discuss.: 31 October 2012

Revised: 23 April 2013 - Accepted: 24 April 2013 - Published: 8 July 2013

\begin{abstract}
Here we report the measurement of the comprehensive isotopic composition $\left(\delta^{15} \mathrm{~N}, \Delta^{17} \mathrm{O}\right.$ and $\left.\delta^{18} \mathrm{O}\right)$ of nitrate at the air-snow interface at Dome C, Antarctica (DC, $\left.75^{\circ} 06^{\prime} \mathrm{S}, 123^{\circ} 19^{\prime} \mathrm{E}\right)$, and in snow pits along a transect across the East Antarctic Ice Sheet (EAIS) between $66^{\circ} \mathrm{S}$ and $78^{\circ} \mathrm{S}$. In most of the snow pits, nitrate loss (either by physical release or UV photolysis of nitrate) is observed and fractionation constants associated are calculated. Nitrate collected from snow pits on the plateau (snow accumulation rate below $\left.50 \mathrm{~kg} \mathrm{~m}^{-2} \mathrm{a}^{-1}\right)$ displays average fractionation constants of $(-59 \pm 10) \% o,(+2.0 \pm 1.0) \%$ and $(+8.7 \pm 2.4) \%$ for $\delta^{15} \mathrm{~N}$, $\Delta^{17} \mathrm{O}$ and $\delta^{18} \mathrm{O}$, respectively. In contrast, snow pits sampled on the coast show distinct isotopic signatures with average fractionation constants of $(-16 \pm 14) \%$, $(-0.2 \pm 1.5) \%$ and $(+3.1 \pm 5.8) \%$, for $\delta^{15} \mathrm{~N}, \Delta^{17} \mathrm{O}$ and $\delta^{18} \mathrm{O}$, respectively. Our observations corroborate that photolysis (associated with a ${ }^{15} \mathrm{~N} /{ }^{14} \mathrm{~N}$ fractionation constant of the order of $-48 \%$ according to Frey et al. (2009)) is the dominant nitrate loss process on the East Antarctic Plateau, while on the coast the loss is less pronounced and could involve both physical release and photochemical processes. Year-round isotopic measurements at DC show a close relationship between the $\Delta^{17} \mathrm{O}$ of atmospheric nitrate and $\Delta^{17} \mathrm{O}$ of nitrate in skin layer snow, suggesting a photolytically driven isotopic equilibrium imposed by nitrate recycling at this interface. Atmospheric nitrate deposition may lead to fractionation of the nitrogen
\end{abstract}

isotopes and explain the almost constant shift of the order of $25 \%$ o between the $\delta^{15} \mathrm{~N}$ values in the atmospheric and skin layer nitrate at DC. Asymptotic $\delta^{15} \mathrm{~N}\left(\mathrm{NO}_{3}^{-}\right)$values calculated for each snow pit are found to be correlated with the inverse of the snow accumulation rate $\left(\ln \left(\delta^{15} \mathrm{~N}(\right.\right.$ as. $)+$ $\left.1)=(5.76 \pm 0.47) \cdot\left(\mathrm{kg} \mathrm{m}^{-2} \mathrm{a}^{-1} / A\right)+(0.01 \pm 0.02)\right)$, confirming the strong relationship between the snow accumulation rate and the degree of isotopic fractionation, consistent with previous observations by Freyer et al. (1996). Asymptotic $\Delta^{17} \mathrm{O}\left(\mathrm{NO}_{3}^{-}\right)$values on the plateau are smaller than the values found in the skin layer most likely due to oxygen isotope exchange between the nitrate photoproducts and water molecules from the surrounding ice. However, the apparent fractionation in $\Delta^{17} \mathrm{O}$ is small, thus allowing the preservation of a portion of the atmospheric signal.

\section{Introduction}

Nitrate $\left(\mathrm{NO}_{3}{ }^{-}\right)$is the final product of the oxidation of nitrogen oxides $\left(\mathrm{NO}_{\mathrm{x}}=\mathrm{NO}+\mathrm{NO}_{2}\right)$ in the atmosphere and one of the most abundant ions found in Antarctic snow (Wolff, 1995). Nitrate concentration profiles in ice cores have long been thought to preserve information regarding atmospheric $\mathrm{NO}_{\mathrm{x}}$ sink variations and changes in the oxidative capacity of ancient atmospheres (Dibb et al., 1998). However, 
the stability of nitrate after deposition to the snow surface has long been questioned (Neubauer and Heumann, 1988; Mayewski and Legrand, 1990) and it is today acknowledged that its deposition is reversible at sites with low snow accumulations rates such as Dome $\mathrm{C}$ or Vostok on the East Antarctic Plateau (Röthlisberger et al., 2000; Blunier et al., 2005; Frey et al., 2009). The physical release of $\mathrm{HNO}_{3}$ (via evaporation and/or desorption, often referred to as simply "evaporation") and the photolysis of $\mathrm{NO}_{3}{ }^{-}$in the UV range ( 280 to $350 \mathrm{~nm}$ ) have been proposed to explain nitrate mass loss from snow (Röthlisberger et al., 2002; Grannas et al., 2007). The relative importance of these photochemical and physical loss processes at a given site is a key issue determining the nitrate transfer function at the air-snow interface.

The effect of post-depositional processes in snow is also reflected in the stable isotopic composition of nitrate (Blunier et al., 2005; Frey et al., 2009). Stable isotope ratios in nitrate are expressed as $\delta^{15} \mathrm{~N}, \Delta^{17} \mathrm{O}$ and $\delta^{18} \mathrm{O}$ and defined as $\delta=R_{\text {spl }} / R_{\text {ref }}-1$, with $R$ denoting the ${ }^{15} \mathrm{~N} /{ }^{14} \mathrm{~N},{ }^{17} \mathrm{O} /{ }^{16} \mathrm{O}$ or ${ }^{18} \mathrm{O} /{ }^{16} \mathrm{O}$ isotope ratios and with the references being $\mathrm{N}_{2}$ AIR and VSMOW for $\mathrm{N}$ and $\mathrm{O}$, respectively. While atmospheric particulate nitrate in non-polar atmospheres is characterized by $\delta^{15} \mathrm{~N}$ values ranging from $-10 \%$ to $+10 \%$ o (Morin et al., 2009), extraordinarily high positive $\delta^{15} \mathrm{~N}$ values up to $+339 \%$ o have been observed in nitrate from the upper snowpack at Dome $\mathrm{C}$ and are attributed to nitrate postdepositional effects (Blunier et al., 2005; Frey et al., 2009).

Oxygen stable isotopes of nitrate provide another specific tracer, $\Delta^{17} \mathrm{O}=\delta^{17} \mathrm{O}-0.52 \times \delta^{18} \mathrm{O}$, more commonly referred to as the "oxygen isotope anomaly" or ${ }^{17} \mathrm{O}$ excess, which quantifies the ${ }^{17} \mathrm{O}$ excess with respect to the mass dependent fractionation rule (where $\delta^{17} \mathrm{O} \approx 0.52 \times \delta^{18} \mathrm{O}$ ). Atmospheric nitrate inherits a large positive oxygen isotopic anomaly from ozone (Michalski et al., 2003; Morin et al., 2011). Other oxidants, $\mathrm{OH}$ for example, possess lower $\Delta^{17} \mathrm{O}$ values (Morin et al., 2011). Therefore, the $\Delta^{17} \mathrm{O}$ of atmospheric nitrate is a function of the relative importance of the oxidants involved in its formation pathways and their isotopic compositions (Michalski et al., 2003; Alexander et al., 2004, 2009; Kunasek et al., 2008; Morin et al., 2008, 2009, 2011). Laboratory studies have shown a small but non-zero fractionation in $\Delta^{17} \mathrm{O}\left(\mathrm{NO}_{3}^{-}\right)$due to photolysis (McCabe et al., 2005). Field observations at the South Pole and Dome $\mathrm{C}$ confirm that the post-depositional fractionation in $\Delta^{17} \mathrm{O}$ is minor compared to the annual signal and an atmospheric signal could likely be conserved (McCabe et al., 2007; Frey et al., 2009). Frey et al. (2009) have also suggested that nitrate oxygen stable isotope ratios at the air-snow interface are in equilibrium; however, to this date, the transfer function of nitrate oxygen isotopes from the atmosphere to the top of the snowpack remains poorly understood.

To quantify the integrated effects of these nitrate postdepositional processes, Blunier et al. (2005) have introduced the calculation of a ${ }^{15} \mathrm{~N} /{ }^{14} \mathrm{~N}$ fractionation constant by applying a simple Rayleigh model which assumes a single and irreversible loss process from snow and the immediate and definitive removal of the nitrate pool removed from the system. This quantity is denoted ${ }^{15} \varepsilon$ by these authors and calculated as follows:

$\ln \left(\delta^{15} \mathrm{~N}_{f}+1\right)={ }^{15} \varepsilon \cdot \ln f+\ln \left(\delta^{15} \mathrm{~N}_{0}+1\right)$,

with $\delta^{15} \mathrm{~N}_{f}$ and $\delta{ }^{15} \mathrm{~N}_{0}$, the $\delta$-values in the initial and remaining snow $\mathrm{NO}_{3}{ }^{-}$and $f$, the remaining nitrate mass fraction.

This approach may oversimplify the combination of processes occurring at the air-snow interface, where the nitrate reservoir may be subject to multiple loss mechanisms in addition to inputs from deposition and internal recycling (Davis et al., 2008; Frey et al., 2009). For this reason, the quantity derived by Blunier et al. (2005) from snow profiles of the isotopic composition of nitrate shall be referred to as an "apparent" fractionation constant, which we denote ${ }^{15} \varepsilon_{\text {app }}$. In what follows, other apparent fractionation constants will be calculated: ${ }^{17} E_{\text {app }}$ and ${ }^{18} \varepsilon_{\text {app }}$ for $\Delta^{17} \mathrm{O}$ and $\delta^{18} \mathrm{O}$, respectively. Note that the $\varepsilon$ values are related to the commonly used fractionation factor $\alpha$ by $\varepsilon=\alpha-1$ (e.g. Criss, 1999).

Nitrogen apparent fractionation constants $\left({ }^{15} \varepsilon_{\text {app }}\right)$ calculated from Dome $\mathrm{C}$ snow pit profiles range from $-49.8 \%$ to $-71.0 \%$ (Blunier et al., 2005; Frey et al., 2009) and indicate that the nitrate fractions left in snow are enriched in ${ }^{15} \mathrm{~N}$ (Blunier et al., 2005; Frey et al., 2009). A quantification of the relative importance of evaporation of $\mathrm{HNO}_{3}$ and $\mathrm{NO}_{3}^{-}$ photolysis at this site requires knowledge of the isotopic fractionation constants associated with each loss process. The ${ }^{15} \mathrm{~N} /{ }^{14} \mathrm{~N}$ fractionation associated with nitrate UV photolysis (denoted ${ }^{15} \varepsilon_{\text {pho }}$ ) is calculated as follows: ${ }^{15} \varepsilon_{\text {pho }}=J^{\prime} / J-1$ with $J^{\prime}$ and $J$, the photolytic rate constant of ${ }^{15} \mathrm{NO}_{3}^{-}$and ${ }^{14} \mathrm{NO}_{3}^{-}$, respectively. The photolytic rate constant $J$ is calculated as follows:

$J=\int \Phi(\lambda, T) \sigma(\lambda, T) I(\lambda, \theta, z) \mathrm{d} \lambda$,

with $I$ the actinic flux, $\Phi$ the quantum yield and $\sigma$ the absorption cross section of ${ }^{14} \mathrm{NO}_{3}^{-} . J^{\prime}$ is calculated using $\sigma^{\prime}$, the absorption cross section of ${ }^{15} \mathrm{NO}_{3}^{-}$which has not yet been measured; therefore, it is often computed using the zero point energy shift model (Miller and Yung, 2000). Frey et al. (2009) used $\sigma$ values of aqueous nitrate which had been observed for ${ }^{14} \mathrm{NO}_{3}^{-}$(Chu and Anastasio, 2003) and calculated that for ${ }^{15} \mathrm{NO}_{3}^{-}$. Along with model estimates of $I$ for Dome C in summer they computed an upper limit ${ }^{15} \varepsilon_{\text {pho }}$ value of $-48 \%$. Based on theoretical calculations, the same authors have estimated that the isotopic fractionation constant associated with the physical release of nitrate (in fact, with the dissociation/protonation step only) should be positive, a result opposed to the large negative ${ }^{15} \varepsilon_{\text {app }}$ value observed in the field. This suggests that the contribution of nitrate evaporation to the overall mass loss is marginal when compared to nitrate UV photolysis (Frey et al., 2009). However, such conclusions are only based on theoretical considerations and lack experimental confirmation. 
In this paper, we investigate the scale and spatial variability of photochemical and physical nitrate loss processes in East Antarctic snow. To achieve this, nitrate in shallow snow pits has been sampled in a wide area in East Antarctica. In order to estimate the isotopic impact of the physical release of nitrate from snow, a simple laboratory experiment was conducted at Dome $\mathrm{C}$ to investigate the isotope effects associated with the physical release of nitrate. The isotopic fractionation constants derived from this experiment are compared to the values expected for nitrate photolysis and to apparent fractionation constants obtained in the field when available. Lastly, we study the isotopic transfer function of nitrate at the air-snow interface, i.e. what is the relationship between $\delta^{15} \mathrm{~N}, \Delta{ }^{17} \mathrm{O}$ and $\delta^{18} \mathrm{O}$ values in atmospheric nitrate and in the skin layer snow nitrate. For this purpose, the seasonal variations of the nitrate stable isotopic composition were measured at Dome $\mathrm{C}$ in the atmospheric particulate nitrate and in the uppermost snow layer. The data reported here together with their interpretation form the basis of a numerical model of the isotopic composition of nitrate in air and snow on icesheets, which is described and used in a companion paper (Erbland et al., 2013).

\section{Experimental setup}

\subsection{Sample collection in the field}

Twenty snow pits were sampled on the East Antarctic Ice Sheet between $66^{\circ} \mathrm{S}$ and $78^{\circ} \mathrm{S}$, from D10 (a coastal location in the vicinity of the French Dumont d'Urville station in Adelie Land) to Dome C (DC, $75^{\circ} 06^{\prime} \mathrm{S}, 123^{\circ} 19^{\prime} \mathrm{E}$, elevation $3233 \mathrm{~m}$ ) and Vostok ( $\mathrm{Vk}, 78^{\circ} 47^{\prime} \mathrm{S}, 106^{\circ} 83^{\prime} \mathrm{E}$, elevation $3488 \mathrm{~m}$ ) (Fig. 1). The Dome C-D10 and Dome CVostok transects were sampled during the austral summers 2007-2008 and 2009-2010 along the French logistical traverse and during flight operations, respectively. Additionally, two snow pits were sampled at Dome C on 26 December 2007 and 16 January 2008. Two others were collected at Vostok during the austral summer 2008-2009. In general, the snow pits were sampled every $2 \mathrm{~cm}$ down to a depth of 20 to $50 \mathrm{~cm}$. In some cases one sample was taken at $90 \mathrm{~cm}$ depth. Nitrate mass fractions in shallow snow pits can be as low as $10 \mathrm{ngg}^{-1}$ (Frey et al., 2009); therefore, for each sample, approximately $1 \mathrm{~kg}$ of snow was collected in a $2 \mathrm{~L}$ sealed plastic bag which secured the collection of an adequate amount of nitrate for the isotopic analysis ( $100 \mathrm{nmol}$ per analysis, Morin et al., 2009) and reruns, if necessary.

Air and surface snow sampling were carried out at Dome $\mathrm{C}$ from January 2009 to January 2010. The first $\mathrm{mm}$ of the noncohesive surface snow, referred to as the "skin layer", was collected approximately every 3 days throughout the campaign and on a wide surface $(\mathrm{ca} .50 \mathrm{~cm} \times 50 \mathrm{~cm})$. Taking into account that different people have sampled skin layer snow and that the softness of the uppermost snow layer is spatially

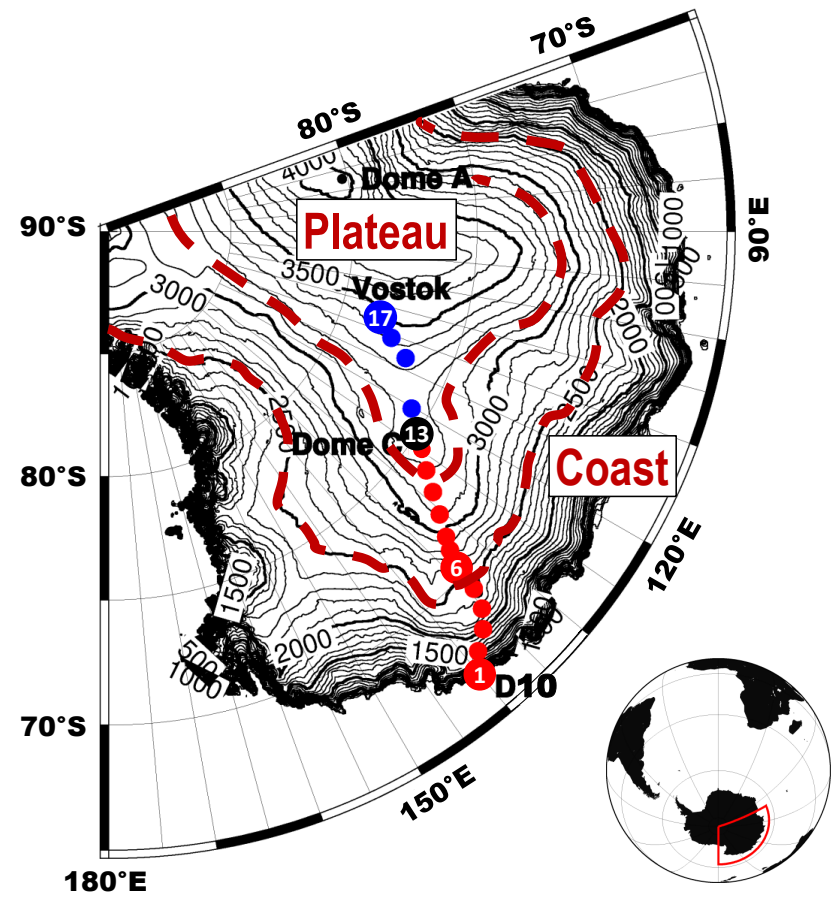

Fig. 1. Snow pit collections in 17 locations in East Antarctica. Spacing of the contour lines is $100 \mathrm{~m}$. The red and blue symbols indicate the locations visited during the austral summers 2007-2008 and 2009-2010, respectively. The Dome C and Vostok sites were sampled two and three times, respectively. The red dashed lines represents the boundaries of the "coast" and "plateau" zones as defined in Sect. 2.4.

heterogeneous, we estimate an average skin layer thickness of $(4 \pm 2) \mathrm{mm}$. Additionally, a $30 \mathrm{~h}$ intensive hourly collection campaign was conducted on 28-29 December 2009. Approximately 300 grams of skin layer snow were collected for each skin layer sample in $1 \mathrm{~L}$ sealed plastic bags (nitrate mass fractions can be smaller than $100 \mathrm{ng} \mathrm{g}^{-1}$ ). Atmospheric samples were collected at DC during the same time period on glass fibre filters $(20.3 \times 25.4 \mathrm{~cm})$ using a high-volume air sampler (HVAS) which has been used during previous campaigns and has been shown to quantitatively trap both particulate nitrate and gaseous $\mathrm{HNO}_{3}$ (Frey et al., 2009). The efficient collection of both particulate and gaseous nitrate on glass fibre filters using the DC HVAS system is supported by the comparison of nitrate atmospheric concentrations measured in this study to $\mathrm{HNO}_{3}$ concentrations obtained from annular denuder tubes operated at DC over the same period of time. The data (unpublished, personal communication, B. Jourdain and S. Preunkert, 2013) show a good agreement between the two collection procedures supporting the efficient collection of $\mathrm{HNO}_{3}$ on glass fibre filters. Details on the sampling procedure with the denuders are found in Legrand et al. (2012), a study which focuses on carboxylic acid but in which major inorganic ions such as $\mathrm{NO}_{3}^{-}$were measured routinely. 
Atmospheric nitrate samples were collected for 37 separate 5-7 day periods at an average flow rate of $1 \mathrm{~m}^{3} \mathrm{~min}^{-1}$ (STP, $T=273.15 \mathrm{~K}$ and $P=1013 \mathrm{hPa}$ ), which was necessary to ensure the collection of a sufficient amount of nitrate for isotopic analysis (atmospheric concentrations can be as low as $1 \mathrm{ng} \mathrm{m}^{-3}$ ). Filters were then removed from the HVAS and placed into clean $50 \mathrm{~cm}^{3}$ centrifuge tubes, put in sealed plastic bags and stored at $-20^{\circ} \mathrm{C}$.

\subsection{Nitrate "physical release" experiment}

An experiment was conducted at Dome $\mathrm{C}$ during the summer campaign 2009-2010 to test the impact of the physical release of nitrate on its isotopic composition. Briefly, surface snow highly concentrated in nitrate (first top $\mathrm{mm}$ ) was collected on 21 December 2009, homogenized and equally distributed into $4 \mathrm{~cm}$ thick layers on three rectangular plates $(40 \mathrm{~cm} \times 20 \mathrm{~cm}, 600 \mathrm{~g}$ on each plate). Each plate was stored in the dark and in three different closed rooms with temperatures of $-10^{\circ} \mathrm{C},-20^{\circ} \mathrm{C}$ and $-30^{\circ} \mathrm{C}$, respectively. The temperature in each room was controlled using an electrical heater and was measured every 2 days. Average temperatures were $(-10.4 \pm 1.3){ }^{\circ} \mathrm{C},(-21.6 \pm 3.8)^{\circ} \mathrm{C}$ and $(-31.4 \pm 1.3){ }^{\circ} \mathrm{C}$ (mean $\pm 1 \sigma$ ), respectively. For the sake of simplicity, in the following we prefer to denote the experiments using their target temperatures (i.e. $-10^{\circ} \mathrm{C},-20^{\circ} \mathrm{C}$ and $-30^{\circ} \mathrm{C}$ ). The snow was subsampled in $1 \mathrm{~L}$ sealed plastic bags over a 2week period and at a 2-day resolution. Snow mass was measured in each sample to monitor sublimation.

\subsection{Chemical and isotopic analysis}

All snow samples (skin layer, snow pit and samples from the "physical release" experiment) were preprocessed in the field except those from the two pits collected at Vostok in 2008-2009, which were double sealed in plastic bags and shipped to France, where they were preprocessed in our laboratory. Each sample was melted at room temperature and $\mathrm{NO}_{3}^{-}$concentrations were determined from an aliquot using a colourimetric method employed routinely at DC (Frey et al., 2009). From nitrate concentrations measured in the melted snow samples, we derive nitrate mass fractions expressed in $\mathrm{ng} \mathrm{g}^{-1}$, denoted as $w\left(\mathrm{NO}_{3}^{-}\right)$in the following. $\mathrm{Ni}-$ trate ions in the remaining melted sample were then concentrated on $0.3 \mathrm{~cm}^{3}$ of an anionic exchange resin (Bio$\operatorname{Rad}^{\mathrm{TM}}$ AG 1-X8, chloride form) and subsequently eluted with $5 \times 2 \mathrm{~cm}^{3}$ of a $\mathrm{NaCl} 1 \mathrm{M}$ solution, allowing for a $100 \%$ recovery (Silva et al., 2000; Frey et al., 2009).

For each "physical release" experiment, we denote the quantities $f_{\text {snow }}(n)$ and $f_{\mathrm{NO}_{3}^{-}}(n)$ which respectively represent the remaining snow and nitrate mass fractions in sample $n$. These two quantities were calculated as follows:

$f_{\text {snow }}(n)=\left[\prod_{i=2}^{n} \frac{m_{\text {snow }}(i, \text { bef })}{m_{\text {snow }}(i-1, \text { aft })}\right] \cdot \frac{m_{\text {snow }}(1, \text { bef })}{m_{\text {snow }}(0)}$ and

$$
\begin{gathered}
f_{\mathrm{NO}_{3}^{-}}(n)=\left[\prod_{i=2}^{n} \frac{m_{\text {snow }}(i, \text { bef }) \cdot w\left(\mathrm{NO}_{3}^{-}\right)(i)}{m_{\text {snow }}(i-1, \mathrm{aft}) \cdot w\left(\mathrm{NO}_{3}^{-}\right)(i-1)}\right] \\
\cdot \frac{m_{\text {snow }}(1, \text { bef }) \cdot w\left(\mathrm{NO}_{3}^{-}\right)(1)}{m_{\text {snow }}(0) \cdot w\left(\mathrm{NO}_{3}^{-}\right)(0)}
\end{gathered}
$$

with $m_{\text {snow }}\left(i\right.$, bef) and $m_{\text {snow }}(i$, aft), the snow mass measured before and after collecting sample $i, w\left(\mathrm{NO}_{3}^{-}\right)(i)$, the nitrate mass fraction measured in sample $i$, and $m_{\text {snow }}(0)$, the initial snow mass placed on the rectangular plate.

Atmospheric nitrate collected on the glass filters was quantitatively extracted in $40 \mathrm{~cm}^{3}$ of ultrapure water via centrifugation using Millipore Centricon ${ }^{\mathrm{TM}}$ filter units. Nitrate concentrations were then determined using the same colourimetric method as described above. Atmospheric nitrate concentrations are further denoted $\gamma\left(\mathrm{NO}_{3}^{-}\right)$and were calculated as the ratio of the total $\mathrm{NO}_{3}^{-}$filter loading to the total volume of air pumped through the filter at STP conditions and expressed in $\mathrm{ng} \mathrm{m}^{-3}$.

Isotope ratios of $\mathrm{NO}_{3}^{-}\left({ }^{15} \mathrm{~N} /{ }^{14} \mathrm{~N},{ }^{17} \mathrm{O} /{ }^{16} \mathrm{O}\right.$ and $\left.{ }^{18} \mathrm{O} /{ }^{16} \mathrm{O}\right)$ were measured on a Thermo Finnigan ${ }^{\mathrm{TM}}$ MAT 253 isotope ratio mass spectrometer, equipped with a GasBench II ${ }^{\mathrm{TM}}$ and coupled to an in-house-built nitrate interface (Morin et al., 2009). Briefly, denitrifying bacteria Pseudomonas aureofaciens convert $\mathrm{NO}_{3}^{-}$in $\mathrm{N}_{2} \mathrm{O}$ in anaerobic conditions (Sigman et al., 2001; Casciotti et al., 2002). $\mathrm{N}_{2} \mathrm{O}$ is then thermally decomposed on a gold surface heated to $900^{\circ} \mathrm{C}$, producing a mixture of $\mathrm{O}_{2}$ and $\mathrm{N}_{2}$ which is then separated by gas chromatography (Kaiser et al., 2007) and injected into the mass spectrometer for the dual $\mathrm{O}$ and $\mathrm{N}$ analysis (Morin et al., 2009).

Isotopic data were corrected for any isotopic effect occurring during the analytical procedure by using the same approach as Morin et al. (2009) and Frey et al. (2009); international reference materials (IAEA USGS-32, 34 and 35) were prepared in an identical way and followed the same analytical procedures. Our choice of the linear definition of $\Delta^{17} \mathrm{O}$ leads to the use of accepted USGS-35 values of $+21.6 \%$ o, $-0.3 \%$ and $+0.0 \%$ for USGS-35, 34 and 32 , respectively. For the same reference material, we use $\delta^{18} \mathrm{O}$ values of $+57.5 \%$ o $-27.9 \%$ and $+25.7 \%$, respectively and $\delta^{15} \mathrm{~N}$ values of $+2.7 \%$, $-1.8 \%$ and $+180 \%$, respectively. This identical treatment includes the use of the same background matrix (ultrapure water and $\mathrm{NaCl} 1 \mathrm{M}$ solution for atmospheric and snow samples, respectively) as well as the same water isotopic composition for the standards and samples. For each batch of 60 samples, the overall accuracy of the method is estimated as the reduced standard deviation of the residuals from the linear regression between the measured reference materials $(n=16)$ and their expected values. For the snow results described here (230 samples in total), the average uncertainty values obtained for $\delta^{18} \mathrm{O}, \Delta^{17} \mathrm{O}$ and $\delta^{15} \mathrm{~N}$ were $2.3 \%$ o, $0.4 \%$ and $0.5 \%$ o, respectively while they are $1.6 \%, 0.5 \%$ and $1.0 \%$ for the 37 atmospheric analysis. 
Note that only $\delta^{15} \mathrm{~N}$ data are available for the "physical release" experiments. The oxygen data were lost due to experimental reasons.

\subsection{Data reduction and complementary data}

The large amount of isotopic data obtained for snow across East Antarctica has been reduced in two ways. First, apparent fractionation constants were calculated following the approach of Blunier et al. (2005) which assumes a Rayleightype single loss process with irreversible removal of nitrate from the snow. The formulation of Blunier et al. (2005) for ${ }^{15} \varepsilon$ can be extended to ${ }^{18} \varepsilon$ and ${ }^{17} E$. Basically, ${ }^{n} \varepsilon(n=15$, 17 or 18) is calculated as the slope of the best linear regression of data in the $\ln \left(1+\delta^{\mathrm{n}}\left(\mathrm{NO}_{3}^{-}\right)\right)$versus $\left(\ln (w(\right.$ as. $\left.)) / \mathrm{ng} \mathrm{g}^{-1}\right)$ space. The isotopic fractionation constants derived from these snow pit data are therefore termed "apparent" (and subscripted "app") because they represent the integrated isotopic effect of the processes involving nitrate in the top decimetres of the snowpack and in the lower atmosphere.

Second, asymptotic values were calculated for each snow pit. In the following, the asymptotic value of the quantity $X$ $\left(=w\left(\mathrm{NO}_{3}^{-}\right), \delta^{15} \mathrm{~N}, \Delta^{17} \mathrm{O}\right.$ and $\left.\delta^{18} \mathrm{O}\right)$ is denoted $X($ as. $)$ and was calculated assuming an exponential behaviour of $X$ with depth $(z)$, as expressed in Eq. (5):

$X(z)=X($ as. $)+[X(0)-X($ as. $)] e^{-z / \eta(X)}$,

with $\eta(X)$, the decay parameter specific to the quantity $X$, which is varied in the $1-30 \mathrm{~cm}$ range and at a $1 \mathrm{~cm}$ resolution. Data from each snow pit were fitted using the above equation, and the best set of parameters $[X(0), X($ as. $), \eta(X)]$ was determined by minimizing the sum of squared residuals. For each snow pit, 1- $\sigma$ uncertainty in the asymptotic quantity $X$ was estimated by calculating the standard deviation of the residuals. Given the above definition of $w$ (as.), $\delta^{15} \mathrm{~N}\left(\right.$ as.), $\Delta^{17} \mathrm{O}$ (as.) and $\delta^{18} \mathrm{O}$ (as.), these terms represent the asymptotic mass fraction and isotopic composition reached by nitrate below the zone of active nitrate mass loss in the top decimetres of snow. In the case of photolysis, this zone is termed the "photic zone" and its lower limit represents the depth at which the actinic flux is mostly null. Radiative transfer of snow is expressed as e-folding depth (Simpson et al., 2002; Domine et al., 2008), which has been observed to be of the order of $10-20 \mathrm{~cm}$ in the top snowpack layers at Dome C and for wavelengths in the $350 \mathrm{~nm}$ to $400 \mathrm{~nm}$ range (France et al., 2011). We note that the observation of France et al. (2011) is consistent with the recent calculation of e-folding depths in the range $18-22 \mathrm{~cm}$ in snow remote from the DC station and at $305 \mathrm{~nm}$, the peak wavelength of nitrate photolysis in the snowpack (Zatko et al., 2013). Thus, in the case of plateau sites such as DC, the photic zone has a thickness of the order of $60 \mathrm{~cm}$ because $95 \%$ of the UV radiation is lost below this depth. Therefore, the asymptotic values derived in this study represent nitrate well below the photic zone, i.e. nitrate which can be considered inert with respect to photoprocesses.

Snow accumulation rates and mean annual temperatures are denoted $A$ and $T_{\mathrm{a}}$, respectively. For the DC and Vostok sites, $A$ and $T_{\mathrm{a}}$ have been obtained from EPICA community members (2004) and Ekaykin et al. (2002), respectively. For the other 15 East Antarctic sites, $A$ and $T_{\mathrm{a}}$ have been interpolated from 1980-2007 simulations of the atmospheric circulation model LMDZ4 (Krinner et al., 2007) and derived from the ERA-Interim reanalysis over the 2000-2008 period (Dee et al., 2011), respectively. The snow accumulation rates, assumed to be stationary in time, are used for the calculation of the asymptotic nitrate mass flux denoted $F$ (as.), expressed in $\mathrm{kg}(\mathrm{N}) \mathrm{m}^{-2} \mathrm{a}^{-1}$ and calculated as $F$ (as.) $=\frac{m_{\mathrm{N}}}{m_{\mathrm{NO}_{3}-}} \times w$ (as.) $\times A$, with $w$ (as.) in $\mathrm{kg}\left(\mathrm{NO}_{3}^{-}\right) \mathrm{kg}(\text { snow })^{-1}$. The quantity $F$ (as.) represents the downward nitrate mass flux which escapes the photic zone towards the deeper snow layers.

The ${ }^{15} \mathrm{~N} /{ }^{14} \mathrm{~N}$ fractionation constant associated with each "physical release" experiment (denoted ${ }^{15} \varepsilon_{\text {phy }}$ ) has been calculated using the approach of Blunier et al. (2005) explained above. In this case we have directly used the remaining nitrate mass fractions $\left(f_{\mathrm{NO}_{3}^{-}}\right)$as in Eq. (1).

\section{Results}

\subsection{Upper snowpack profiles of $\mathrm{NO}_{3}^{-}$in East Antarctica}

Figures $2 \mathrm{a}$ and $2 \mathrm{~b}$ show the nitrate mass fraction and isotopic composition $\left(\delta^{15} \mathrm{~N}\right.$ and $\left.\Delta^{17} \mathrm{O}\right)$ in each of the 20 snow pits sampled in this study. $\mathrm{NO}_{3}^{-}$mass fraction profiles in each snow pit show a decreasing trend over the uppermost $1-2 \mathrm{dm}$ of snow. The decrease is moderate (around $50 \%$ ) at sites close to D10 and dramatic on the plateau, at Dome C, Vostok and sites in between those locations. For example, every snow pit sampled at DC shows nitrate mass fractions reduced by $80 \%$ in the top $10 \mathrm{~cm}$ (panel 13 on Fig. 2a), which is consistent with all previous observations (Röthlisberger et al., 2000; Blunier et al., 2005; Frey et al., 2009).

A similar spatial variability is also observed for $\delta^{15} \mathrm{~N}$ (Fig. 2a), with values increasing by $250 \%$ (to values as high as $+359.7 \%$ in the S4 pit) over the top $50 \mathrm{~cm}$ of snow on the plateau, while a weak increase of $10 \%$ is observed on the coast. The same applies for $\delta^{18} \mathrm{O}$, with the lowermost value found in the S3 pit (+10.9\%o) (data not shown here but provided in Fig. 20, Supplement). The high enrichment in $\delta^{15} \mathrm{~N}$ and depletion in $\delta^{18} \mathrm{O}$ observed at the Dome $\mathrm{C}$ site (up to $+250 \%$ and $+30 \%$, respectively) are consistent with previous studies (Blunier et al., 2005; Frey et al., 2009). The ${ }^{17} \mathrm{O}$ excess in surface snow nitrate varies between $23 \%$ and $38 \%$ o. On the East Antarctic Plateau, the $\Delta^{17} \mathrm{O}$ values in nitrate of the upper snow layers are of the order of $30 \%$ and decrease to $20-25 \%$ at $50 \mathrm{~cm}$ depth. Some $\Delta^{17} \mathrm{O}\left(\mathrm{NO}_{3}^{-}\right)$profiles at plateau sites show oscillations with amplitudes of 


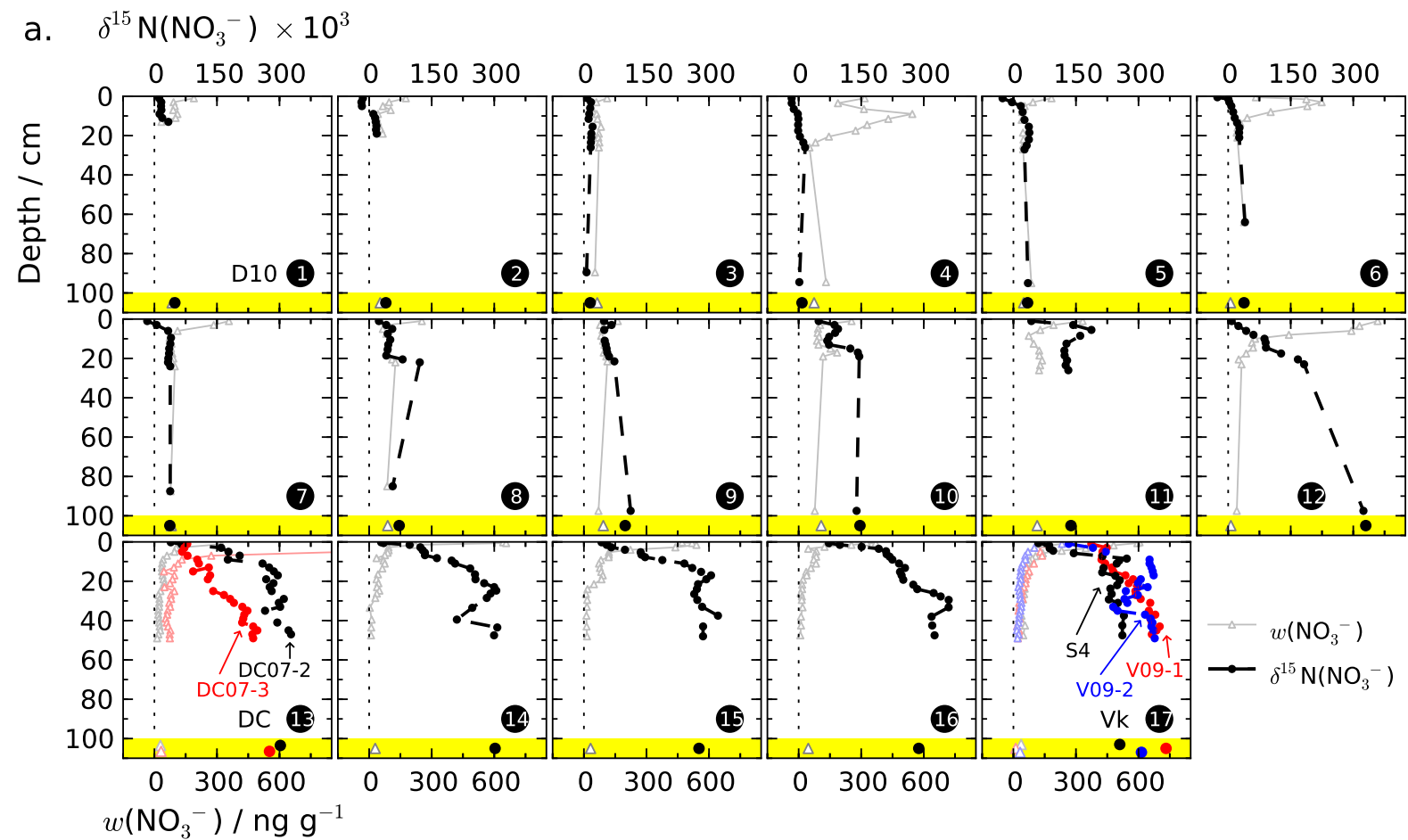

b. $\Delta^{17} \mathrm{O}\left(\mathrm{NO}_{3}^{-}\right) \times 10^{3}$

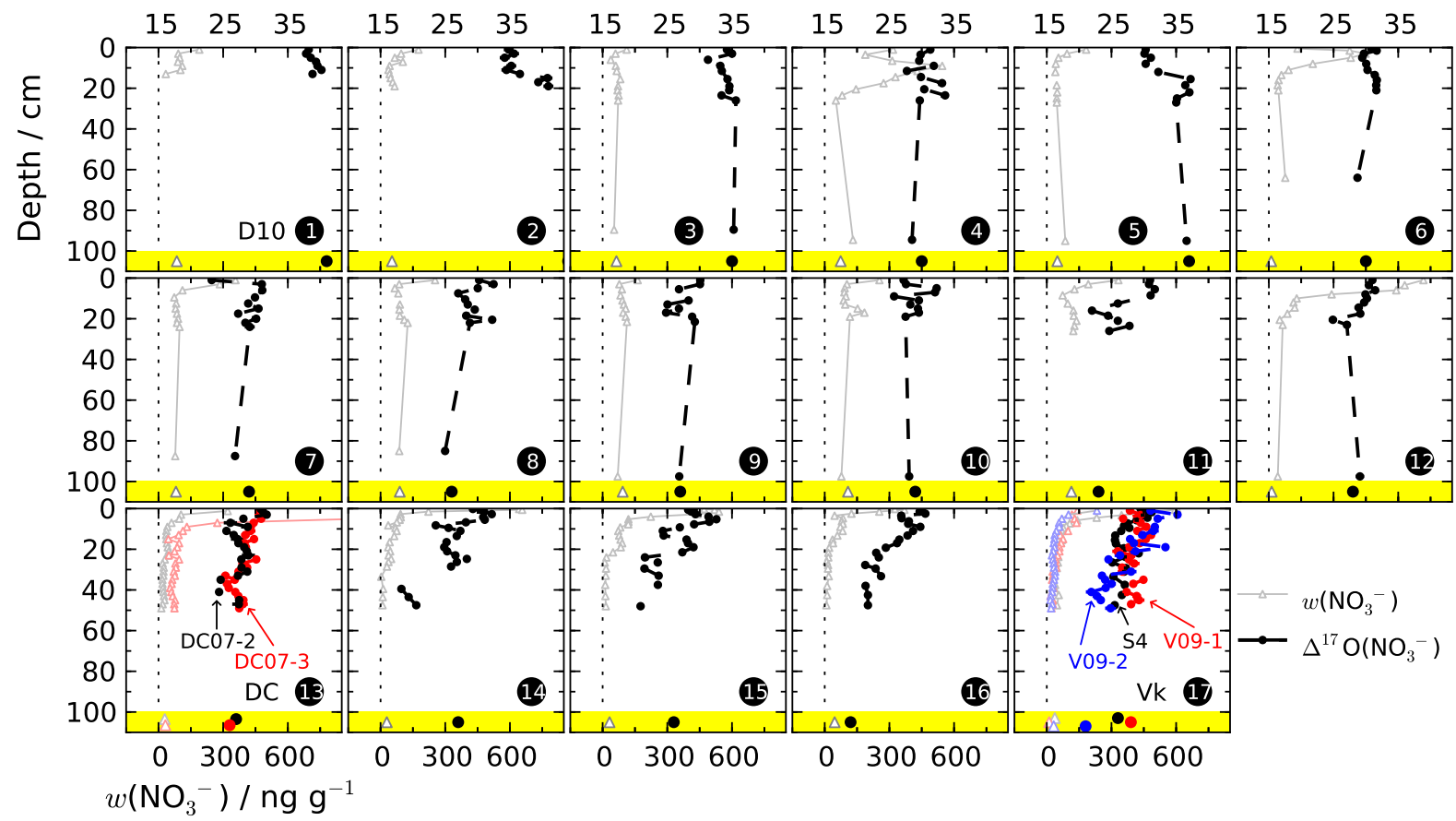

Fig. 2. Nitrate mass fraction and (a) $\delta^{15} \mathrm{~N}$ and (b) $\Delta^{17} \mathrm{O}$ profiles in the upper snowpack in East Antarctica. The numbers refer to the individual locations identified in Fig. 1 and Table 1. For the Dome $\mathrm{C}$ and Vostok sites, the colours refer to the different snow pits sampled in those locations: DC07-2 in black and DC07-3 in red, S4 in black, V09-1 in red and V09-2 in blue, respectively. The triangles and circles in the yellow shaded area below $1 \mathrm{~m}$ in each panel represent the asymptotic nitrate mass fraction $(w($ as. $))$ and $\delta^{15} \mathrm{~N}\left(\delta^{15} \mathrm{~N}(\right.$ as. $\left.)\right)$ and $\Delta^{17} \mathrm{O}$ $\left(\Delta^{17} \mathrm{O}(\right.$ as. $\left.)\right)$ calculated for each pit. 
Table 1. Asymptotic nitrate isotopic composition $\left(\delta^{18} \mathrm{O}\right.$ (as.), $\Delta^{17} \mathrm{O}($ as. $)$ and $\delta^{15} \mathrm{~N}($ as. $\left.)\right)$ and apparent isotopic fractionation constants $\left({ }^{15} \varepsilon_{\text {app }}\right.$, ${ }^{17} E_{\text {app }}$ and ${ }^{18} \varepsilon_{\text {app }}$ for $\delta^{18} \mathrm{O}, \Delta{ }^{17} \mathrm{O}$ and $\delta^{15} \mathrm{~N}$, respectively) observed in snow pits across East Antarctica together with all of the existing data previously published for this area: (1) this study, (2) Frey et al. (2009) and (3) Blunier et al. (2005). Mean annual $2 \mathrm{~m}$ temperatures are derived from the ERA-Interim reanalysis over the 2000-2008 period (Dee et al., 2011) or from observations for the Dome C and Vostok sites. One- $\sigma$ uncertainties in the fractionation constants are based on the propagation of the error in the isotope ratios (this study and Frey et al., 2009, after Taylor, 1997) and Monte Carlo analysis for the Blunier et al. (2005) results. One- $\sigma$ uncertainties in the asymptotic values are obtained as explained in the method section.

\begin{tabular}{|c|c|c|c|c|c|c|c|c|c|c|c|c|c|c|c|}
\hline Site & $\begin{array}{r}\text { Lat./ } \\
0\end{array}$ & $\begin{array}{r}\text { Lon./ } \\
\circ\end{array}$ & $\begin{array}{l}T_{\mathrm{a}} / \\
{ }^{\circ} \mathrm{C}\end{array}$ & $\mathrm{kg} \mathrm{m}^{-2} \mathrm{a}^{-1}$ & $\begin{array}{l}\text { Dist. to } \\
\text { D10/km }\end{array}$ & $\begin{array}{r}\text { Elev./ } \\
\mathrm{m}\end{array}$ & $\begin{array}{l}w \text { (as.)/ } \\
\mathrm{ngg}^{-1}\end{array}$ & $\begin{array}{r}\delta^{18} \mathrm{O} \text { (as.) } \\
\% \circ\end{array}$ & $\begin{array}{r}\Delta^{17} \mathrm{O}(\text { as. }) \\
\% \circ\end{array}$ & $\begin{array}{r}\delta^{15} \mathrm{~N} \text { (as.) } \\
\% \circ\end{array}$ & ${ }^{18} \varepsilon_{\text {app }}$ & $\begin{array}{r}{ }^{17} E_{\text {app }} \\
\% \text {. }\end{array}$ & ${ }^{15} \varepsilon_{\text {app }}$ & Code & Ref. \\
\hline 1 (D10) & -66.7 & 139.828 & -12 & 558 & 0 & 296 & $85 \pm 23$ & $101 \pm 3$ & $41 \pm 1$ & $49 \pm 5$ & $5.2 \pm 1.5$ & $-0.1 \pm 0.7$ & $-13.2 \pm 2.0$ & D10 & 1. \\
\hline 2 & -67.4111 & 138.619 & -21 & 515 & 95 & 1586 & $53 \pm 17$ & $94 \pm 8$ & $44 \pm 2$ & $40 \pm 5$ & $8.4 \pm 5.5$ & $-1.0 \pm 2.0$ & $-24.3 \pm 8.5$ & II & 1. \\
\hline 3 & -67.91 & 136.696 & -26 & 334 & 190 & 1986 & $64 \pm 12$ & $92 \pm 4$ & $35 \pm 1$ & $15 \pm 4$ & $8.0 \pm 5.2$ & $2.0 \pm 1.3$ & $0.3 \pm 5.4$ & IV & 1. \\
\hline 4 & -68.5261 & 135.239 & -31 & 246 & 281 & 2350 & $74 \pm 122$ & $72 \pm 8$ & $30 \pm 2$ & $8 \pm 5$ & $-3.9 \pm 3.2$ & $-0.2 \pm 0.8$ & $-9.0 \pm 3.6$ & VI & 1. \\
\hline 5 & -69.3098 & 134.33 & -34 & 216 & 369 & 2558 & $49 \pm 13$ & $93 \pm 3$ & $37 \pm 1$ & $34 \pm 4$ & $-2.4 \pm 4.8$ & $-2.0 \pm 1.9$ & $-34.2 \pm 8.4$ & VIII & 1. \\
\hline 6 & -70.2511 & 134.103 & -36 & 160 & 458 & 2663 & $11 \pm 101$ & $69 \pm 5$ & $30 \pm 1$ & $38 \pm 5$ & $-2.7 \pm 1.6$ & $-0.5 \pm 0.3$ & $-11.4 \pm 5.1$ & $\mathrm{X}$ & 1. \\
\hline 7 & -71.606 & 132.993 & -38 & 121 & 556 & 2823 & $81 \pm 21$ & $66 \pm 6$ & $29 \pm 1$ & $37 \pm 3$ & $-6.0 \pm 4.4$ & $-1.5 \pm 1.3$ & $-31.3 \pm 2.8$ & XII & 1. \\
\hline 8 & -71.5327 & 132.84 & -39 & 96 & 618 & 2951 & $89 \pm 18$ & $53 \pm 6$ & $26 \pm 2$ & $72 \pm 21$ & $-3.1 \pm 6.7$ & $1.2 \pm 2.1$ & $-3.9 \pm 24.5$ & XIV & 1. \\
\hline 9 & -72.319 & 130.466 & -42 & 68 & 721 & 3108 & $93 \pm 14$ & $49 \pm 5$ & $27 \pm 1$ & $99 \pm 11$ & $1.4 \pm 8.3$ & $2.7 \pm 2.7$ & $-43.0 \pm 23.0$ & XVI & 1. \\
\hline 10 & -73.993 & 128.711 & -44 & 53 & 826 & 3178 & $108 \pm 31$ & $44 \pm 9$ & $29 \pm 2$ & $147 \pm 21$ & $-15.2 \pm 7.2$ & $-1.1 \pm 1.7$ & $-4.4 \pm 27.9$ & XVIII & 1. \\
\hline 11 & -73.844 & 126.912 & -45 & 43 & 926 & 3201 & $114 \pm 19$ & $40 \pm 5$ & $23 \pm 2$ & $138 \pm 22$ & $12.3 \pm 6.3$ & $2.3 \pm 2.8$ & $-58.5 \pm 20.5$ & XX & 1. \\
\hline 12 & -74.7067 & 124.552 & -47 & 34 & 1045 & 3260 & $13 \pm 76$ & $32 \pm 3$ & $28 \pm 1$ & $330 \pm 12$ & $8.9 \pm 1.4$ & $1.3 \pm 0.4$ & $-65.7 \pm 11.9$ & XXII & 1. \\
\hline 13 (DC) & -75.1 & 123.35 & -54 & 25 & 1101 & 3233 & $0 \pm 44$ & - & - & $151 \pm 21$ & - & - & $-53.9 \pm 9.7$ & $\mathrm{DC} 03$ & 3. \\
\hline 13 (DC) & -75.1 & 123.35 & -54 & 25 & 1101 & 3233 & $0 \pm 27$ & $29 \pm 3$ & $23 \pm 1$ & $334 \pm 23$ & $6.4 \pm 2.5$ & $0.9 \pm 0.2$ & $-49.8 \pm 10.4$ & DC04 & 2. \\
\hline 13 (DC) & -75.1 & 123.35 & -54 & 25 & 1101 & 3233 & $45 \pm 12$ & $27 \pm 5$ & $28 \pm 2$ & $305 \pm 28$ & $9.4 \pm 2.2$ & $2.3 \pm 0.7$ & $-74.3 \pm 11.4$ & DC07-1 & 2. \\
\hline 13 (DC) & -75.1 & 123.35 & -54 & 25 & 1101 & 3233 & $29 \pm 13$ & $26 \pm 3$ & $27 \pm 1$ & $302 \pm 20$ & $9.4 \pm 1.5$ & $1.7 \pm 0.5$ & $-72.7 \pm 8.3$ & DC07-2 & 1. \\
\hline 13 (DC) & -75.1 & 123.35 & -54 & 25 & 1101 & 3233 & $32 \pm 157$ & $28 \pm 5$ & $26 \pm 1$ & $276 \pm 17$ & $6.1 \pm 1.8$ & $1.2 \pm 0.3$ & $-40.0 \pm 8.6$ & DC07-3 & 1. \\
\hline 14 & -75.7161 & 120.226 & -49 & 28 & 1211 & 3243 & $46 \pm 44$ & $12 \pm 5$ & $19 \pm 2$ & $288 \pm 25$ & $12.2 \pm 2.1$ & $2.7 \pm 0.5$ & $-46.6 \pm 8.3$ & S1 & 1. \\
\hline 15 & -76.841 & 112.987 & -49 & 22 & 1437 & 3369 & $22 \pm 48$ & $24 \pm 9$ & $20 \pm 2$ & $302 \pm 22$ & $7.2 \pm 2.1$ & $2.0 \pm 0.4$ & $-52.8 \pm 7.2$ & S2 & 1. \\
\hline 16 & -77.6779 & 110.55 & -49 & 20 & 1540 & 3414 & $32 \pm 30$ & $20 \pm 6$ & $19 \pm 1$ & $338 \pm 25$ & $8.7 \pm 1.3$ & $2.7 \pm 0.2$ & $-54.6 \pm 5.1$ & S3 & 1. \\
\hline $17(\mathrm{Vk})$ & -78.47 & 106.8 & -55 & 21 & 1661 & 3488 & $37 \pm 20$ & $32 \pm 7$ & $26 \pm 1$ & $255 \pm 27$ & $8.5 \pm 1.5$ & $1.5 \pm 0.2$ & $-63.2 \pm 4.9$ & S4 & 1. \\
\hline 17 (Vk) & -78.47 & 106.8 & -55 & 21 & 1661 & 3488 & $11 \pm 9$ & $24 \pm 5$ & $28 \pm 1$ & $366 \pm 16$ & $3.9 \pm 1.8$ & $0.2 \pm 0.5$ & $-59.7 \pm 3.5$ & V09-1 & 1. \\
\hline 17 (Vk) & -78.47 & 106.8 & -55 & 21 & 1661 & 3488 & $32 \pm 9$ & $24 \pm 8$ & $21 \pm 2$ & $307 \pm 31$ & $11.1 \pm 3.1$ & $4.4 \pm 1.0$ & $-62.2 \pm 9.4$ & V09-2 & 1. \\
\hline
\end{tabular}

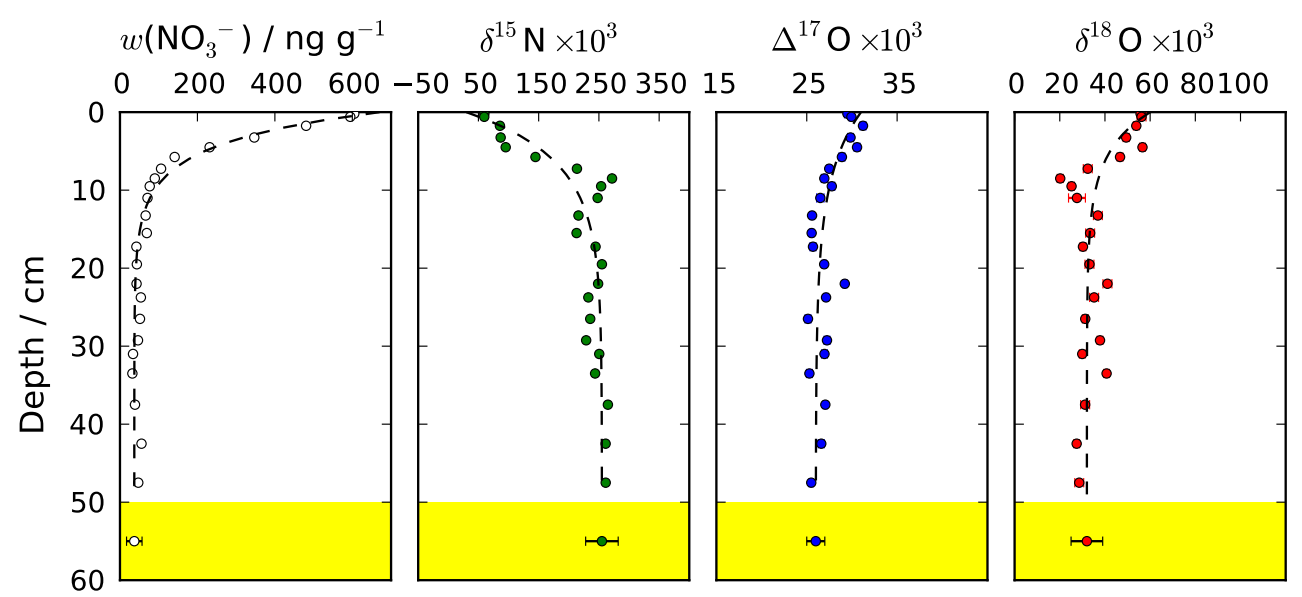

Fig. 3. Detailed view of nitrate mass fraction and isotopic composition profiles for snow pit S4 (panel 17 on Fig. $2 \mathrm{a}$ and b. The black dashed lines represent the fit to the data used to derive the asymptotic values as expressed in Eq. (5).

5-7\%o (e.g. snow pit S2, panel 15 on Fig. 2b or Fig. 19 in Supplement), consistent with previous observations by Frey et al. (2009) at DC. At such low accumulation sites, $\Delta^{17} \mathrm{O}\left(\mathrm{NO}_{3}^{-}\right)$also shows a decreasing trend with depth with a reduction of up to $10 \%$.

Figure 3 presents an example of the data reduction procedure used to derive the asymptotic values in the case of snow pit S4 sampled at Vostok (Eq. 5). The other snow pits, together with the related exponential fits, are individually displayed in the Supplement. Figures $4 \mathrm{a}-\mathrm{i}$ and Table 1 present the reduced data together with the data previously published for Dome C ("DC03", Blunier et al., 2005; "DC04" and "DC07-1", Frey et al., 2009). The uncertainty derived for the asymptotic values are small in most cases (Table 1 and Fig. $4 \mathrm{~d}-\mathrm{f}$ ). Values of the asymptotic isotope ratios show significant spatial gradients across East Antarctica (Fig. 4d$\mathrm{f}$, respectively): in comparison to values found close to the coast, $\delta^{18} \mathrm{O}$ (as.) and $\Delta^{17} \mathrm{O}($ as.) are lower by more than $80 \%$ and $20 \%$, respectively, and $\delta^{15} \mathrm{~N}$ (as.) is higher by more than $300 \%$ at Vostok. Values of asymptotic nitrate mass fractions 


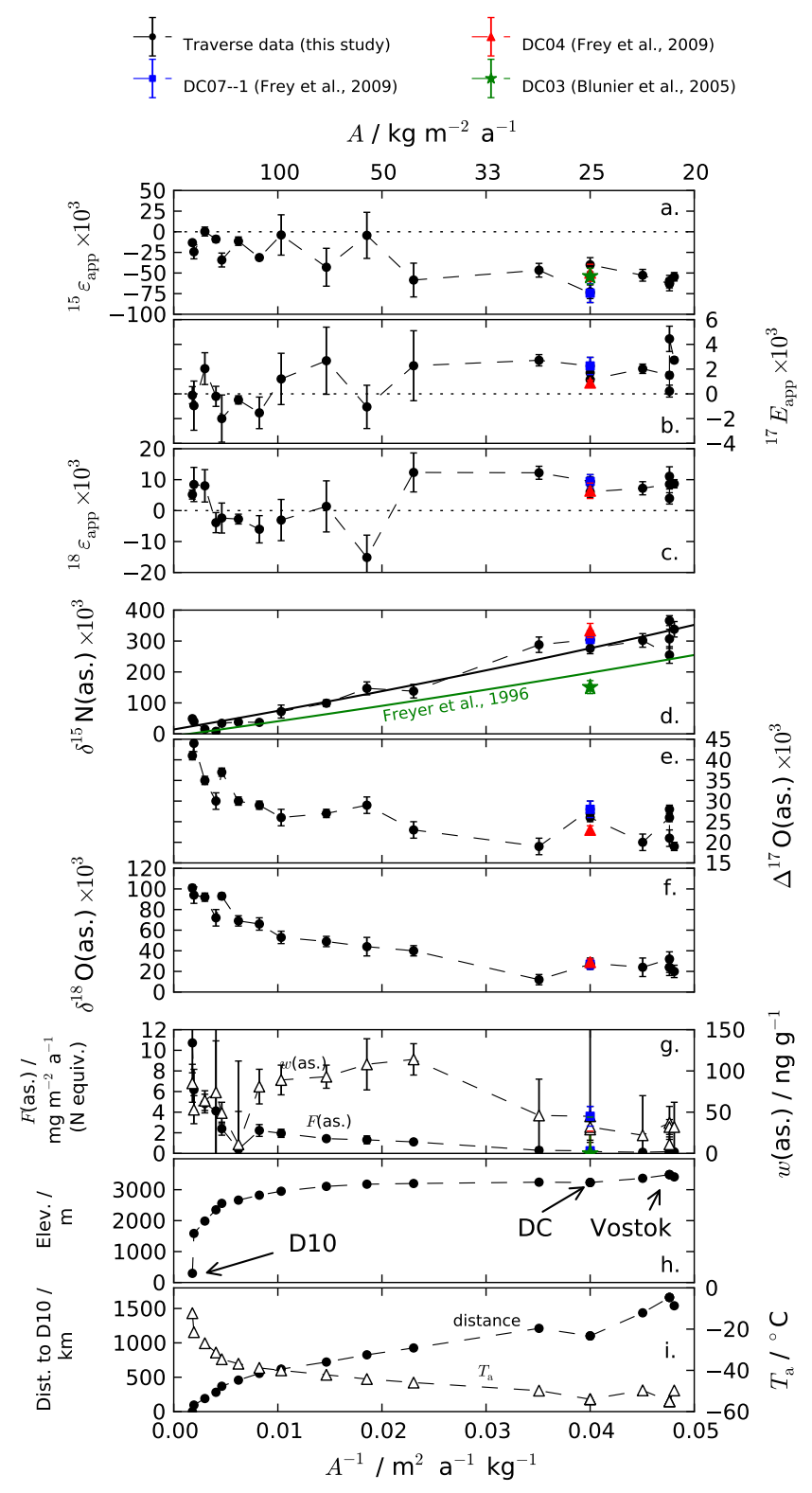

Fig. 4. Reduced data for the snow pits collected in East Antarctica plotted as a function of the snow accumulation rates (top $\mathrm{x}$ axis) and their inverse (bottom $\mathrm{x}$-axis). (a-c) ${ }^{15} \mathrm{~N} /{ }^{14} \mathrm{~N},{ }^{17} \mathrm{O}$ excess and ${ }^{18} \mathrm{O} /{ }^{16} \mathrm{O}$ apparent fractionation constants $\left({ }^{15} \varepsilon_{\text {app }},{ }^{17} E_{\text {app }}\right.$ and ${ }^{18} \varepsilon_{\text {app }}$, respectively). (d-e) Asymptotic $\delta^{15} \mathrm{~N}, \Delta^{17} \mathrm{O}$ and $\delta^{18} \mathrm{O}$ values. The solid lines in (d) are fits to the data of this study (black) and those of Freyer et al. (1996) (green) following the approach of the latter authors. (g) Asymptotic nitrate mass flux ( $F($ as.), the downward nitrate mass flux which escapes the photic zone) and mass fractions $w$ (as.), (h) site's elevation and (i) site's distance to D10 and mean annual temperature $T_{\mathrm{a}}$. Data for previously published pits are marked by a blue square (DC07-1, Frey et al., 2009), a red triangle (DC04, Frey et al., 2009) and a green star (Blunier et al., 2005).

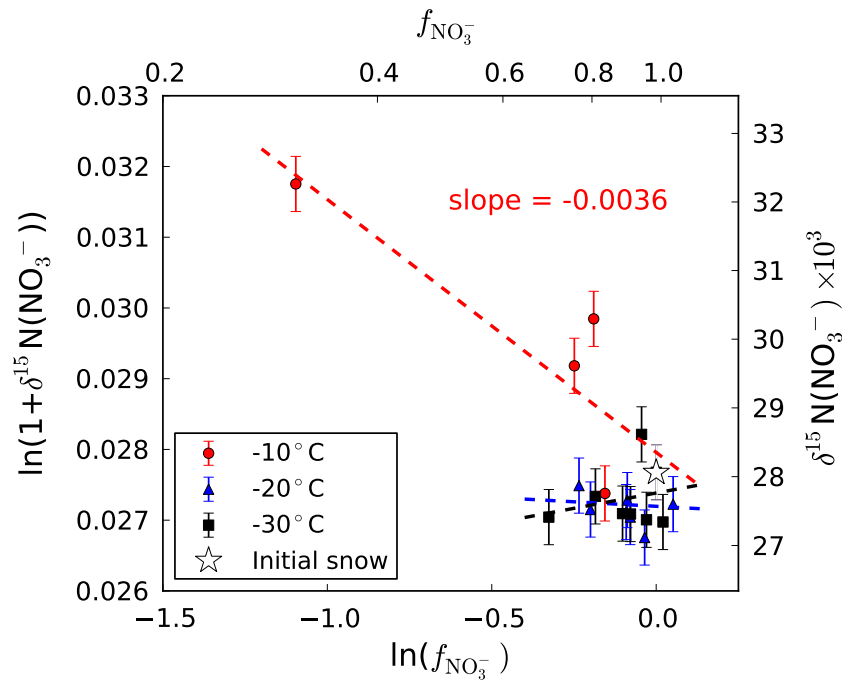

Fig. 5. Nitrate "physical release" experiments: $1+\delta^{15} \mathrm{~N}\left(\mathrm{NO}_{3}^{-}\right)$and the remaining nitrate mass fraction $\left(f_{\mathrm{NO}_{3}^{-}}\right)$are plotted in a logarithmic scale. The red line is a linear fit to the data obtained for the experiment conducted at $-10^{\circ} \mathrm{C}$, where a Rayleigh-type single loss process is assumed.

also show a spatial variability with lower concentrations on the plateau ( $w$ (as.) values generally below $50 \mathrm{ng} \mathrm{g}^{-1}$ ) than on the coast (values up to $120 \mathrm{ng} \mathrm{g}^{-1}$ ) (Fig. $4 \mathrm{~g}$ ). The asymptotic nitrate flux is an order of magnitude lower on the plateau $\left(F(\right.$ as. $\left.)<1 \mathrm{mg}(\mathrm{N}) \mathrm{m}^{-2} \mathrm{a}^{-1}\right)$ than at $\mathrm{D} 10$.

Figure $4 \mathrm{a}-\mathrm{c}$ as well as Table 1 present the apparent isotopic fractionation constants derived for each snow pit. Apparent isotopic fractionation constants obtained for DC in this study range from $+6.1 \%$ to $+9.4 \%$ o for ${ }^{18} \varepsilon_{\text {app }}$, from $+1.2 \%$ to $+1.7 \%$ for ${ }^{17} E_{\text {app }}$ and from $-72.7 \%$ to $-40.0 \%$ o for ${ }^{15} \varepsilon_{\text {app }}$, and are within the range of previous observations at this site (Fig. 4a-c and Table 1).

\section{2 ${ }^{15} \mathrm{~N} /{ }^{14} \mathrm{~N}$ fractionation associated with the physical release of nitrate}

Figure 5 shows the results of the "physical release" experiments carried out at DC in parallel with field observations. The initial snow had a nitrate mass fraction of $1471 \mathrm{ngg}^{-1}$ and $\delta^{15} \mathrm{~N}$ value of $+28.1 \%$, which are typical values for the skin layer at DC. Table 2 gives the total nitrate and snow mass fractions lost at the end of each experiment. The minimum nitrate and snow mass losses $(17 \%$ and $1 \%)$ are observed for the experiment conducted at $-30^{\circ} \mathrm{C}$. On the other hand, the maximum nitrate and snow mass losses $(67 \%$ and $93 \%$ ) are observed for the experiment conducted at $-10^{\circ} \mathrm{C}$, although this experiment was 4 days shorter than the other two.

$\delta^{15} \mathrm{~N}$ in snow nitrate of the $-30{ }^{\circ} \mathrm{C}$ and $-20^{\circ} \mathrm{C}$ experiments remained constant with averages $( \pm 1-\sigma)$ of $(27.5 \pm$ $0.2) \% o$ and $(27.6 \pm 0.4) \%$, respectively. However, nitrate in 
Table 2. Nitrate "physical release" experiments: isotopic fractionation constants calculated for each of the three experiments conducted at $-10{ }^{\circ} \mathrm{C},-20^{\circ} \mathrm{C}$ and $-30{ }^{\circ} \mathrm{C}(1-\sigma$ uncertainties calculated as in Frey et al., 2009).

\begin{tabular}{lrrrr}
\hline $\begin{array}{l}\text { Temp./ } \\
{ }^{\circ} \mathrm{C}\end{array}$ & $\begin{array}{r}\text { Duration/ } \\
\text { days }\end{array}$ & $\begin{array}{r}\mathrm{NO}_{3}^{-} \text {fraction } \\
\text { lost/\% }\end{array}$ & $\begin{array}{r}\text { Snow fraction } \\
\text { lost } / \%\end{array}$ & ${ }^{15} \varepsilon_{\text {phy }} \pm 1 \sigma / \% \circ$ \\
\hline-10 & 10 & 67 & 93 & $-3.6 \pm 1.1$ \\
-20 & 14 & 21 & 11 & $-0.3 \pm 1.2$ \\
-30 & 14 & 17 & 1 & $0.9 \pm 3.5$ \\
\hline
\end{tabular}

the $-10^{\circ} \mathrm{C}$ experiment was $4.2 \%$ higher after 10 days. The $-30{ }^{\circ} \mathrm{C}$ and $-20{ }^{\circ} \mathrm{C}$ experiments yield ${ }^{15} \mathrm{~N} /{ }^{14} \mathrm{~N}$ fractionation constants not significantly different from zero $\left({ }^{15} \varepsilon_{\text {phy }}\right.$ values of $(+0.9 \pm 1.5) \% o$ and $(-0.3 \pm 1.2) \%$, respectively), while the $-10^{\circ} \mathrm{C}$ experiment is associated with a ${ }^{15} \varepsilon_{\text {phy }}$ value which is significantly negative: $(-3.6 \pm 1.1) \%$ o (Table 2).

\subsection{Annual atmospheric and skin layer variations at Dome C}

\subsubsection{Annual cycle of $\mathrm{NO}_{3}^{-}$concentrations}

Figure $6 \mathrm{~b}$ shows the atmospheric and skin layer nitrate concentrations observed at Dome C during the period of 20092010. Atmospheric $\mathrm{NO}_{3}^{-}$concentrations remained relatively low and steady for most of the year, with an average value of $(5.9 \pm 4.1) \mathrm{ng} \mathrm{m}^{-3}$ during the polar night period, i.e. from March to September 2009. Sporadic concentration maxima greater than $>90 \mathrm{ng} \mathrm{m}^{-3}$ occured in spring, concurrently with the return of continuous sunlight at DC (see UV-B* dose in Fig. 6a). During this period of maximum photochemical activity (October to December), $\mathrm{NO}_{3}^{-}$concentrations reached an average value of $(61.9 \pm 19.2) \mathrm{ng} \mathrm{m}^{-3}$, then decreased sharply to values lower than $30 \mathrm{ng} \mathrm{m}^{-3}$ in early summer (January 2010), in agreement with previous observations at DC in 2007 (Frey et al., 2009) and at the South Pole in 2004 (McCabe et al., 2006).

$\mathrm{NO}_{3}^{-}$mass fractions in the skin layer snow exhibit a seasonal pattern similar to that observed for the atmosphere: low and steady mass fractions, $(161 \pm 50) \mathrm{ngg}^{-1}$, are observed during polar night, followed by a sharp increase to values in the $600-1400 \mathrm{ng} \mathrm{g}^{-1}$ range in the spring and early summer, consistent with previous results obtained for daily surface snow samples at Halley, Antarctica (Wolff et al., 2008). Temporal variations of $\mathrm{NO}_{3}^{-}$mass in the skin layer are offset from those observed in the atmosphere by a period of approximately 3-4 weeks. For instance, while atmospheric $\mathrm{NO}_{3}^{-}$concentration increases above its background level in mid-October, skin layer $\mathrm{NO}_{3}^{-}$mass fraction does not begin to increase until mid-November.

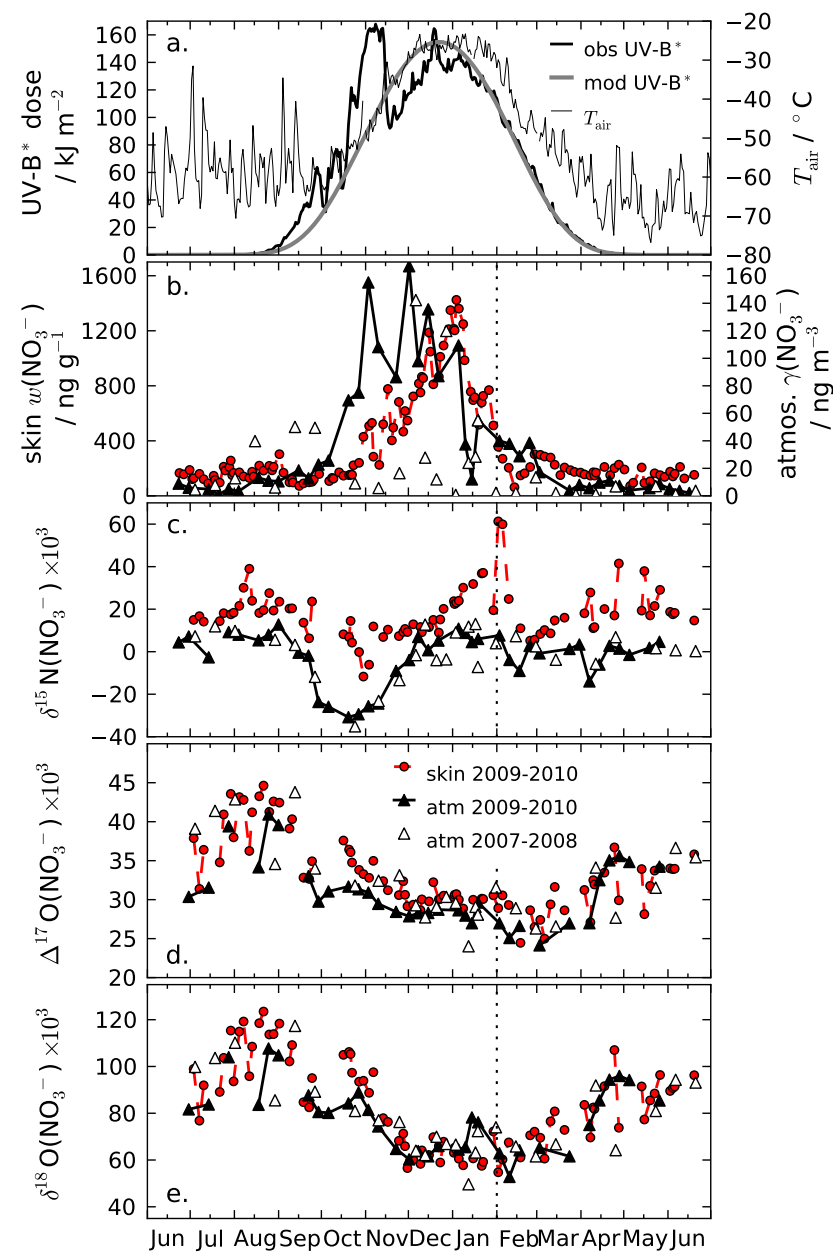

Fig. 6. DC atmospheric and skin layer $\mathrm{NO}_{3}^{-}$in 2007-2008 (Frey et al., 2009) and 2009-2010 and skin layer nitrate in 2009-2010: (a) DC daily air temperature (thin line) and modelled UV-B* (280 $320 \mathrm{~nm}$ ) for observed and a constant (290 DU) $\mathrm{O}_{3}$ column density (black and grey lines) and a snow albedo of 0.9 , (b) $\mathrm{NO}_{3}^{-}$concentrations, (c) $\delta^{15} \mathrm{~N}\left(\mathrm{NO}_{3}^{-}\right)$, (d) $\Delta^{17} \mathrm{O}\left(\mathrm{NO}_{3}^{-}\right)$and (e) $\delta^{18} \mathrm{O}\left(\mathrm{NO}_{3}^{-}\right)$in atmospheric nitrate in 2007-2008 and 2009-2010 (open and closed triangles, respectively) and in skin layer nitrate in 2009-2010 (red circles). The vertical dashed line shows the starting date of the datasets.

\subsubsection{Annual cycle of nitrate isotopic composition}

Figures $6 \mathrm{c}$ and $6 \mathrm{~d}$ show the annual variations of the atmospheric and skin layer $\delta^{15} \mathrm{~N}\left(\mathrm{NO}_{3}^{-}\right)$and $\Delta^{17} \mathrm{O}\left(\mathrm{NO}_{3}^{-}\right)$at $\mathrm{DC}$ in 2009-2010, which are described below. $\delta^{15} \mathrm{~N}\left(\mathrm{NO}_{3}^{-}\right)$shows the same features as those reported in 2007-2008 by Frey et al. (2009): from March to August, $\delta^{15} \mathrm{~N}$ in atmospheric nitrate fluctuates between $-14.0 \%$ and $+12.8 \%$ with a mean value of $(1.6 \pm 6.5) \%$. Along with the increase of surface temperatures and $\mathrm{UV}$ radiation, $\delta^{15} \mathrm{~N}$ in atmospheric nitrate gradually decreases to reach its lowest value $(-30.8 \%$ o compared to $-35.0 \%$ for Frey et al., 2009) in mid-October. The 
annual weighted $\delta^{15} \mathrm{~N}$ value is $-6.5 \%$. In the skin layer, $\delta^{15} \mathrm{~N}\left(\mathrm{NO}_{3}^{-}\right)$has an annual weighted mean of $+18.2 \%$. The lowest values $(-11.7 \%$ ) are found in spring, at the end of October. After this minimum, $\delta^{15} \mathrm{~N}$ steadily increases to reach values above $+30 \%$ ob the end of the summer. While the polar night is characterized by skin layer snow featuring $\delta^{15} \mathrm{~N}$ values of $(21.1 \pm 7.7) \%$, drastic variations of more than $40 \%$ can be observed between two consecutive samples. On average, $\delta^{15} \mathrm{~N}$ in the skin layer nitrate is of the order of $25 \%$ o higher than $\delta^{15} \mathrm{~N}$ in the atmospheric nitrate.

$\Delta{ }^{17} \mathrm{O}$ for the atmospheric nitrate sampled at Dome $\mathrm{C}$ in 2009-2010 is consistent with previous measurements in 2007-2008: the highest values (> 40\%o) are observed during August, while the signal flattens in summer to reach its lowermost values (around $29 \%$, Frey et al., 2009). $\Delta{ }^{17} \mathrm{O}$ in skin layer nitrate displays a similar trend, but with less variations. $\Delta^{17} \mathrm{O}$ in the two reservoirs are shifted by a few $\%$ on average annually. This $\Delta{ }^{17} \mathrm{O}$ difference is greater at the end of the winter ( $>5 \%$ in mid-Oct.) than in summer (within the analytical error in January, Fig. 6d). The annual massweighted $\Delta{ }^{17} \mathrm{O}$ averages calculated for the atmospheric and skin layer nitrate are $29.4 \%$ and $31.7 \%$, respectively.

\subsection{Intensive skin layer collection at Dome $\mathbf{C}$}

Between 28 December and 29 December 2009, nitrate in the skin layer snow at Dome $\mathrm{C}$ show average $( \pm 1 \sigma)$ mass fraction, $\delta^{15} \mathrm{~N}, \Delta^{17} \mathrm{O}$ and $\delta^{18} \mathrm{O}$ values of $(1261 \pm 105) \mathrm{ng} \mathrm{g}^{-1}$, $(17.0 \pm 1.0) \%$, $(28.6 \pm 1.2) \%$ and $(56.2 \pm 3.6) \%$ o, respectively, consistent with the annual data obtained for this period and shown in Fig. 6 (27 data in total; data shown in Supplement, Fig. 24). The small scatters observed in the isotope ratios in skin layer nitrate $(1.0 \%, 1.2 \%$ and $3.6 \%$ for $\delta^{15} \mathrm{~N}, \Delta{ }^{17} \mathrm{O}$ and $\delta^{18} \mathrm{O}$, respectively) are very close to the analytical errors obtained for those samples $(0.9 \%, 1.0 \%$ and $2.3 \%$, respectively). Hence, the observed small variations in $\delta^{15} \mathrm{~N}$ and $\Delta^{17} \mathrm{O}$ in hourly skin layer nitrate collections are not quantitatively significant. The chosen sampling method (i.e. one skin layer sample collection every 3 days on average) is therefore appropriate to track annual variations in the isotopic composition of nitrate in this reservoir.

\section{Discussion}

\subsection{Relative contribution of nitrate post-depositional processes in East Antarctica}

\subsubsection{Process-specific ${ }^{15} \mathrm{~N} /{ }^{14} \mathrm{~N}$ fractionation constants}

Although the ${ }^{15} \mathrm{~N} /{ }^{14} \mathrm{~N}$ fractionation constant estimated for the physical release of nitrate suffers from a number of caveats, we note that it is significantly different from the estimated value for UV photolysis in DC conditions $(-48 \%$, Frey et al., 2009), thus allowing us to disentangle the nitrogen isotopic effects of both processes. The ${ }^{15} \varepsilon_{\text {phy }}$ value derived from the experiment conducted at $-10^{\circ} \mathrm{C}$ is negative $(-3.6 \%$, Table 2$)$, indicating that the remaining snow is enriched in ${ }^{15} \mathrm{~N}$, a result consistent with the fact that lower vapour pressure is expected for the heavier isotope. In contrast, Frey et al. (2009) calculated a fractionation constant of positive sign. They calculated the evaporation fractionation constant as that of the single dissociation/protonation step which may not be the crucial process in the calculation of this variable.

The ${ }^{15} \varepsilon_{\text {phy }}$ values derived from the $-30^{\circ} \mathrm{C}$ and $-20^{\circ} \mathrm{C}$ experiments are not significantly different from zero, which seems to be linked to the small nitrate mass loss obtained after 14 days for these two experiments conducted at low temperatures $\left(17 \%\right.$ and $21 \%$ for the $-30^{\circ} \mathrm{C}$ and $-20^{\circ} \mathrm{C}$ experiments, respectively, compared to $67 \%$ at $-10^{\circ} \mathrm{C}$ and after 10 days). The different temperatures used in this experiment should not be seen as relevant for different Antarctic site conditions but rather as a way to force nitrate mobility through snow metamorphism and to achieve significant nitrate mass loss in order to allow for the calculation of fractionation constants.

The experiment presented in this study does not provide a definitive quantification of the processes at play under natural conditions. Indeed, under the conditions in these experiments, the atmospheric reservoir above the snow was not replenished constantly and nitrate diffusion in snow was neither forced by temperature gradients nor by wind pumping. Also, the experiment conducted at $-10^{\circ} \mathrm{C}$ is the only one which has led to a significant nitrate loss. We note that such temperature conditions rarely occur in the Dome C surface snow. Although not all the conditions were controlled during the three different "physical release" experiments, we note that redeposition of $\mathrm{HNO}_{3}$ to the snow may be limited given that all three experiments were conducted in closed spaces with wide walls (surface greater than $40 \mathrm{~m}^{2}$ ) where atmospheric $\mathrm{HNO}_{3}$ was more likely to stick on walls rather than on snow. This is further supported by the experiments conducted at $-20^{\circ} \mathrm{C}$ and $-30^{\circ} \mathrm{C}$ where no nitrate gain was observed. Another great advantage of this experiment is its use of natural snow as opposed to previous laboratory experiments (e.g. McCabe et al., 2005).

For all the reasons provided above, the fractionation constants estimated for the "physical release" experiments must be considered with care. In the case where nitrate loss by physical release was enhanced (i.e. in the $-10^{\circ} \mathrm{C}$ experiment), we have estimated that this process is associated with an isotopic fractionation constant $(-3.6 \%$ ) which is significantly different from the estimated value for UV photolysis (-48\%, Frey et al., 2009). Because these two loss processes seem to have such different nitrogen isotopic signatures, the determination of the dominant process at play appears to be possible on the basis of ${ }^{15} \varepsilon_{\text {app }}$ values obtained from snow pits and their comparison to estimated values of ${ }^{15} \varepsilon_{\text {pho }}$ and ${ }^{15} \varepsilon_{\text {phy }}$. At Dome C, Frey et al. (2009) have obtained ${ }^{15} \varepsilon_{\text {app }}$ as low as $-71.0 \%$, which was interpreted as strong evidence 
for the fact that photolysis dominates nitrate loss under such conditions.

The low dynamics observed over 14 days in the "physical release" experiments conducted at $-30^{\circ} \mathrm{C}$ and $-20^{\circ} \mathrm{C}$ contrast with the high variation found in mass fraction of the skin layer nitrate at Dome C (Fig. 6b). Therefore, a loss process faster than nitrate evaporation is necessary to explain the high variations in skin layer nitrate mass fraction at DC. We also note that some drastic changes in skin layer nitrate mass fractions between two consecutive samples could be linked to uncertainty in sampling depth as well as enhanced nitrate deposition through the precipitation of diamond dust (cloud formed at ground level and composed of tiny ice crystals).

Despite its uncertainities, the present experiment does not support that the loss could be dominated by direct reemission of $\mathrm{HNO}_{3}$ or snow metamorphism at Dome C. We do not imply here that the physical release of $\mathrm{HNO}_{3}$ does not occur at all in Dome $\mathrm{C}$ snow since this statement would contradict the observations of the loss from snow of $\mathrm{HCl}$ (Röthlisberger et al., 2003), another volatile compound which is not known to undergo photolysis in DC conditions. Therefore, we cautiously acknowledge that nitrate may well be mobilized by physical processes at Dome C; however, the strength of UV photolysis is such that it dominates the overall net loss from the snow.

\subsubsection{Dominant loss process on the plateau and the coast}

In what follows, the East Antarctic Ice Sheet is divided into three zones with respect to the observed ${ }^{15} \varepsilon_{\text {app }},{ }^{18} \varepsilon_{\text {app }}$ and ${ }^{17} E_{\text {app }}$ values: the coast (features $A>200 \mathrm{~kg} \mathrm{~m}^{-2} \mathrm{a}^{-1}$, $T_{\mathrm{a}}>-35^{\circ} \mathrm{C}$ and elev. $<2500 \mathrm{~m}$ ), the plateau (features $A<$ $50 \mathrm{~kg} \mathrm{~m}^{-2} \mathrm{a}^{-1}, T_{\mathrm{a}} \leq-45^{\circ} \mathrm{C}$ and elev. $>3150 \mathrm{~m}$ ) (Fig. 1) and a transition zone between the two. Along the D10-DC and DC-Vostok transects presented in this study, sites in the coastal zone are within $400 \mathrm{~km}$ to D10 and beyond $1100 \mathrm{~km}$ to D10 for sites in the plateau zone. The coast, transition and plateau zones contain 5, 5 and 7 sites, respectively. Table 3 presents the average, standard deviation and minimum and maximum values for each apparent fractionation constant calculated for the coastal and plateau zones. Plateau sites are characterized by a low average ${ }^{15} \varepsilon_{\text {app }}$ value of $(-59 \pm 10) \%$, and average ${ }^{18} \varepsilon_{\text {app }}$ and ${ }^{17} E_{\text {app }}$ values of $(+8.7 \pm 2.4) \%$ and $(+2.0 \pm 1.0) \%$, respectively. In contrast, coastal sites are characterized by a moderate ${ }^{15} \mathrm{~N} /{ }^{14} \mathrm{~N}$ apparent fractionation constant, $(-16 \pm 14) \%$ on average, and ${ }^{18} \varepsilon_{\text {app }}$ and ${ }^{17} E_{\text {app }}$ values which are insignificantly different from zero: $(+3.1 \pm 5.8) \%$ and $(-0.2 \pm 1.5) \%$ o, respectively.

Uncertainties in the calculation of the apparent fractionation constants for individual snow pits reveal the degree to which the assumed single-step Rayleigh model is reasonable in explaining the observed isotopic features at depth. On the plateau and on the coast the uncertainties are small, as shown in Fig. 4a, b and $\mathrm{c}$ and in Table 1. This observation suggests that the single-step Rayleigh fractionation model assumed
Table 3. Apparent fractionation constants ${ }^{n} \varepsilon(n=15,17,18$ for $\delta^{15} \mathrm{~N}, \Delta^{17} \mathrm{O}$ and $\delta^{18} \mathrm{O}$, respectively) in East Antarctica: average, standard deviation, minimum and maximum values. For the plateau we have also used all previously published data (see in Table 1).

\begin{tabular}{lrrr}
\hline & ${ }^{15} \varepsilon_{\text {app }} / \% 0$ & ${ }^{18} \varepsilon_{\text {app }} / \% 0$ & ${ }^{17} E_{\text {app }} / \% 0$ \\
\hline Plateau $\left(T_{\mathrm{a}} \leq-45^{\circ} \mathrm{C}\right)$ & & & \\
\hline ave. & -59.2 & +8.7 & +2.0 \\
$\pm 1-\sigma$ & +10.4 & +2.4 & +1.0 \\
$\min$. & -74.3 & +3.9 & +0.2 \\
$\max$. & -40.0 & +12.3 & +4.4 \\
\hline Coast $\left(T_{\mathrm{a}}>-35^{\circ} \mathrm{C}\right)$ & & & \\
\hline ave. & -16.1 & +3.1 & -0.2 \\
$\pm 1-\sigma$ & +13.5 & +5.8 & +1.5 \\
$\min$. & -34.2 & -3.9 & -2.0 \\
$\max$. & +0.3 & +8.4 & +2.0 \\
\hline & & &
\end{tabular}

for the calculation of ${ }^{15} \varepsilon_{\text {app }},{ }^{18} \varepsilon_{\text {app }}$ and ${ }^{17} E_{\text {app }}$ is used appropriately and indicates that nitrate loss from snow is governed by a single process in these zones. In contrast, uncertainties are large for sites in the transition zone where nitrate mass loss from snow may be due to a combination of multiple loss processes.

Nitrate UV photolysis and physical release have competitive isotopic effects given their two distinct ${ }^{15} \varepsilon$ signatures. As discussed above, the use of an apparent fractionation constant allows for the quantification of the integrated isotopic effect of nitrate post-depositional processing in the upper snow and lower atmosphere. At this interface, nitrogen isotopes of nitrate may undergo fractionation through other processes such as local recycling from the redeposition of either re-oxidized photochemical products or directly emitted $\mathrm{HNO}_{3}$. In what follows, we neglect any possible ${ }^{15} \mathrm{~N} /{ }^{14} \mathrm{~N}$ fractionation due to re-oxidation and redeposition because the difference they may cause at the air-snow interface (of the order of $25 \%$ on average at DC) is small when compared to the enrichments of more than $+200 \%$ which are observed in the snow profiles. Under this assumption, the estimates of ${ }^{15} \varepsilon_{\text {phy }}$ and ${ }^{15} \varepsilon_{\text {pho }}$ can be directly compared to ${ }^{15} \varepsilon_{\text {app }}$ to determine the relative importance of the two loss processes. Therefore, in the extreme case, where the UV photolysis dominates the mass loss, ${ }^{15} \varepsilon_{\text {app }}$ values derived from snow pits must be close to ${ }^{15} \varepsilon_{\text {pho. }}$.

On the plateau the average ${ }^{15} \varepsilon_{\text {app }}$ is $(-59 \pm 10) \%$ (Table 3 ), a value close to an estimate of ${ }^{15} \varepsilon_{\text {pho }}$ based on a photolyic fractionation model and DC radiation conditions for summer solstice $(<-48 \%$, Frey et al., 2009). This average ${ }^{15} \varepsilon_{\text {app }}$ value is characteristic of the plateau zone, given the small standard deviation associated with it. From this, we conclude that nitrate UV photolysis not only dominates the nitrate ${ }^{15} \mathrm{~N} /{ }^{14} \mathrm{~N}$ fractionation but also the nitrate mass loss on the plateau. In this zone, the physical release of 
nitrate therefore leads to only a minor net mass loss, but it is nevertheless possible that this process is responsible for nitrate mobility within the snowpack, at the macroscopic scale; for example, under the effect of $\mathrm{H}_{2} \mathrm{O}$ mobility (Pinzer et al., 2012). The positive and significant average ${ }^{17} E_{\text {app }}$ and ${ }^{18} \varepsilon_{\text {app }}$ values observed on the plateau, $(+2.0 \pm 1.0) \%$ and $(+8.7 \pm 2.4) \%$ o (Table 3), are consistent with the fact that UV photolysis dominates nitrate loss. Indeed, they reflect the fact that a fraction of the photoproducts undergo an isotopic exchange with a source of $\mathrm{O}$ atoms featuring low $\delta^{18} \mathrm{O}$ and $\Delta{ }^{17} \mathrm{O}$ values (such as $\mathrm{H}_{2} \mathrm{O}$ molecules of snow which feature $\left.\Delta{ }^{17} \mathrm{O}\left(\mathrm{H}_{2} \mathrm{O}\right) \approx 0\right)$ and an extensive cage recombination leading to the re-formation of nitrate (McCabe et al., 2005). Figures $4 \mathrm{~b}$ and $4 \mathrm{i}$ further show that ${ }^{17} E_{\text {app }}$ is weakly sensitive to the local annual average temperature for East Antarctic Plateau sites. The oxygen isotopic exchange and cage recombination effects undergone by nitrate photoproducts may therefore be rather insensitive to temperature variations in the $-55^{\circ} \mathrm{C}$ to $-47^{\circ} \mathrm{C}$ range. This result could be highly relevant for the analysis of the $\Delta^{17} \mathrm{O}$ profiles of nitrate trapped in deep ice cores retrieved from plateau sites such as Dome $\mathrm{C}$ or Vostok.

In contrast, coastal sites are characterized by a moderate average ${ }^{15} \mathrm{~N} /{ }^{14} \mathrm{~N}$ fractionation, $(-16 \pm 14) \%$, and average oxygen isotopic fractionation constants not significantly different from zero: $(+3.1 \pm 5.8) \%$ and $(-0.2 \pm 1.5) \%$ for ${ }^{18} \varepsilon_{\text {app }}$ and ${ }^{17} E_{\text {app }}$, respectively. In this zone, the observed nitrate mass loss rates are small (Fig. 2a) and a precise discussion of the relative contribution of the physical and photochemical loss processes remains delicate. We however note that the average ${ }^{15} \varepsilon_{\text {app }}$ value observed on the coast is closer to the experimental estimate of the ${ }^{15} \varepsilon_{\text {phy }}$ value than to the estimated ${ }^{15} \varepsilon_{\text {pho }}$ value, which suggests that the physical release of nitrate is a greater contributor to nitrate mass loss from snow than UV photolysis in this area. This conclusion is further supported by the observation of average ${ }^{17} E_{\text {app }}$ and ${ }^{18} \varepsilon_{\text {app }}$ values not significantly different from zero in this zone, which suggests an absence of oxygen isotope exchange. On the coast, the physical release of nitrate is likely encouraged by the high air temperatures combined with the high wind speeds which are prevalent in this area (Gallet et al., 2011). In contrast, we note that the high snow accumulation rates featuring coastal sites cannot explain the greater contribution of the physical release of nitrate to the total observed mass loss since this variable would equally act on the two loss processes by limiting nitrate residence time in the zone of active loss (the photic zone when considering photolysis).

Lastly, the transition zone between the coast and the plateau shows ${ }^{15} \varepsilon_{\text {app }}$ values which vary well within the average values observed for the two extreme geographic zones, indicating a transition from a "coastal" to a "plateau" regime. This transition zone appears to host a combination of nitrate loss processes.

\subsection{A dynamic equilibrium at the air-snow interface at Dome $\mathbf{C}$ in summer}

The fact that nitrate UV photolysis dominates the mass loss from snow on the plateau has important implications in terms of local $\mathrm{N}$ cycling. Given the short photochemical lifetimes of $\mathrm{NO}_{\mathrm{x}}$ and $\mathrm{HNO}_{3}$ above the plateau during summer (approx. $15 \mathrm{~h}$, Davis et al., 2008 and $3.5 \mathrm{~h}$, Huey et al., 2004, respectively, for South Pole conditions), the release of $\mathrm{NO}_{\mathrm{x}}$ through nitrate UV photolysis initiates complex and rapid local recycling of nitrogen at the air-snow interface (Davis et al., 2008; Morin et al., 2009; Frey et al., 2009). This rapid recycling (loss, oxidation, deposition) may result in an equilibrium between atmospheric and surface snow nitrate, as previously suggested by Frey et al. (2009). Here we test this hypothesis in light of our observations at the air-snow interface at Dome C.

Isotopic fractionation occurring during atmospheric sampling cannot explain the average $25 \%$ observed in nitrogen15 isotope between snow and atmospheric nitrate. Indeed, this would require that nitrate is not quantitatively collected on filter. However, nitrate photolysis occurring during summer may explain the average $25 \%$ enrichment observed in $\delta^{15} \mathrm{~N}$ in snow versus the atmospheric nitrate at Dome C. Indeed, the negative ${ }^{15} \mathrm{~N} /{ }^{14} \mathrm{~N}$ fractionation constant estimated for UV photolysis $\left({ }^{15} \varepsilon_{\text {pho }}=-48 \%\right.$, (Frey et al., 2009)) means that the emitted $\mathrm{N}$ mass fraction is depleted in ${ }^{15} \mathrm{~N}$ (Savarino et al., 2007; Morin et al., 2009; Frey et al., 2009) as observed for atmospheric nitrate in spring and summer (Fig. 6c). As a first-order estimate, the photolytically produced $\mathrm{NO}_{\mathrm{x}}$ should be depleted by $48 \%$ o compared to the initial nitrate in snow. Such an important difference is not observed between the atmosphere and the skin layer. One possible explanation for this involves the snow layers directly below the skin layer, which may also participate in $\mathrm{NO}_{\mathrm{x}}$ production. These deeper layers contain nitrate which displays increasing $\delta^{15} \mathrm{~N}$ values with increasing depth (panel 13 on Fig. 2a). Therefore, the $\mathrm{NO}_{\mathrm{x}}$ produced from these layers also have increasing $\delta^{15} \mathrm{~N}$ values with depth. As a result, photolysis leads to the snowpack emission of $\mathrm{NO}_{\mathrm{x}}$ which may have a higher $\delta^{15} \mathrm{~N}$ value than that in skin layer nitrate. Furthermore, the skin layer not only experiences a pure nitrate mass loss but also a gain in nitrate through atmospheric deposition. Deposition could result in a fractionation of the nitrogen isotopes in nitrate, thus complicating the interpretation of observations at the air-snow interface.

During winter, nitrate photolysis cannot be invoked to explain the shift in $\delta^{15} \mathrm{~N}$ between the atmosphere and skin layer nitrate. However, the shift in $\left.\delta^{15} \mathrm{~N}_{(} \mathrm{NO}_{3}^{-}\right)$observed in winter could be linked to the existence of a fractionation of the nitrogen isotopes during deposition. Our data suggest that the ${ }^{15} \mathrm{~N} /{ }^{14} \mathrm{~N}$ fractionation constant associated with the deposition reaction $\mathrm{HNO}_{3(\mathrm{~g})} \longrightarrow \mathrm{NO}_{3 \text { (skin) }}^{-}$and denoted ${ }^{15} \varepsilon_{\text {dep }}$ must be positive and this sign may relate to the nature of the deposition of atmospheric nitrate to the snow. However, this 
discussion is beyond the scope of the present paper because the average $\delta^{15} \mathrm{~N}$ shift at the air-snow interface $(24.7 \%$ ) is small when compared to the asymptotic $\delta^{15} \mathrm{~N}$ values measured at Dome C and Vostok (up to $+300 \%$ ).

Conversely, $\Delta{ }^{17} \mathrm{O}$ values for atmospheric and skin layer nitrate have similar trends, but with a difference (with respect to the analytical uncertainty) which decreases throughout the spring and summer from $5 \%$ to almost $0 \%$ in January (Fig. 6d). The spring/summer variations of this difference could be linked to the different size of the skin layer and atmospheric nitrate reservoirs. Indeed, the skin layer reservoir is on average 100 times larger than the atmospheric compartment when considering a constant boundary layer of $50 \mathrm{~m}$ and a constant snow density of $250 \mathrm{~kg} \mathrm{~m}^{-3}$ for a $4 \mathrm{~mm}$ skin layer. Therefore, changes in $\Delta^{17} \mathrm{O}$ in the atmospheric nitrate will occur in $\Delta^{17} \mathrm{O}$ in the atmospheric nitrate with a temporal delay. Throughout the summer, the $\Delta^{17} \mathrm{O}$ difference decreases and becomes almost zero, thus indicating an isotopic equilibrium at the DC air-snow interface. $\Delta^{17} \mathrm{O}$ in skin layer nitrate could therefore be used as a recorder of $\Delta{ }^{17} \mathrm{O}$ in atmospheric nitrate - a feature of particular interest at sites where atmospheric sampling is not feasible. Lastly, we acknowledge that skin layer nitrate is a more reliable recorder of the oxygen isotopic composition of atmospheric nitrate than nitrate is in the first $10 \mathrm{~cm}$ of snow (Frey et al., 2009) because $\Delta^{17} \mathrm{O}$ is already affected by post-depositional processes at this depth (e.g. panels 13 to 17 in Fig. 2b).

The concentration maximum in atmospheric nitrate precedes that in the skin layer by 3-4 weeks (Fig. 6b). This temporal offset could be attributed to a faster flux of reactive nitrogen from the snow to the atmosphere under the effect of UV photolysis when compared to a slower nitrate deposition flux over this period. To test this hypothesis, we have assumed a pure dry deposition of nitrate from the atmosphere to the snow with a constant deposition velocity of $v_{\text {dep, app }}$ (expressed in $\mathrm{cm} \mathrm{s}^{-1}$ ). We then calculate the cumulative nitrate mass deposited from the atmosphere to the snow starting from the end of the winter and compare this quantity to the nitrate mass in the skin layer over the same period of time. The temporal offset in nitrate concentration observed between the two compartments can be reproduced by using

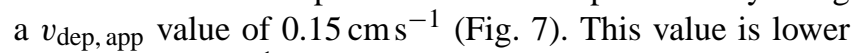
than the $0.8 \mathrm{~cm} \mathrm{~s}^{-1}$ value calculated for the dry deposition of $\mathrm{HNO}_{3}$ in South Pole conditions (Huey et al., 2004). However, it should be borne in mind that our estimate represents an "apparent" deposition velocity for summer conditions at DC because a re-emission flux of reactive nitrogen from the skin layer to the atmosphere also occurs.

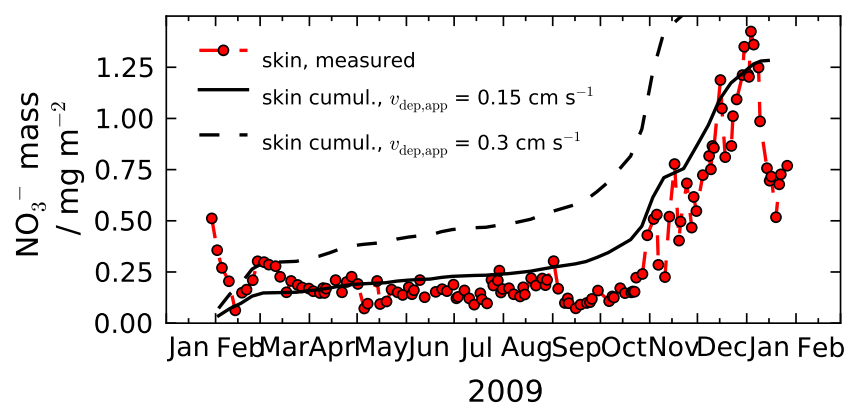

Fig. 7. Cumulative dry deposition from the atmosphere to the skin layer for two different vertical apparent deposition velocities.

\subsection{Interpretation of the asymptotic isotopic composition of nitrate on the Antarctic Plateau}

\subsection{1 $\delta^{15} \mathrm{~N}($ as.) sensitivity to snow accumulation rates}

Snow accumulation rate is an important driver of $\delta^{15} \mathrm{~N}$ in snow nitrate, as evidenced by the strong correlation between the asymptotic $\delta^{15} \mathrm{~N}$ values and the inverse of snow accumulation rates: $\ln \left(\delta^{15} \mathrm{~N}(\right.$ as. $\left.)+1\right)=(5.76 \pm 0.47)$. $\left(\mathrm{kg} \mathrm{m}^{-2} \mathrm{a}^{-1} / A\right)+(0.01 \pm 0.02)(1-\sigma$ uncertainties calculated as in Taylor, 1997) (Fig. 4d). We note that this correlation has been previously emphasized in the pioneering work of Freyer et al. (1996) on the basis of the measurement of nitrogen isotope ratios in nitrate archived in ice cores from Dome C, South Pole, Summit (Greenland) and D47, a location between D10 and DC. These archived values can then be considered to be asymptotic values, as defined in this study, when assuming that nitrate and its isotopic composition are preserved in the firn and in the ice. The sensitivity of $\delta^{15} \mathrm{~N}$ (as.) to $1 / A$ (slope of $5.76 \pm 0.47$ ) reported in this study is close to the finding of Freyer et al. (1996), who reported a slope of 4.68. The detailed discussion of the small differences in slope is beyond the scope of this study.

Local variations in snow accumulation rate may contribute to explain the variations in $\delta^{15} \mathrm{~N}$ (as.) observed at the same site. For instance, in Vostok, we report three snow pits which have comparable ${ }^{15} \varepsilon_{\text {app }}$ values $(-63.2 \%$ o, $-59.7 \%$ o and $-62.2 \%$ or S4, V09-1 and V09-2, respectively, Table 1) but which have different $\delta^{15} \mathrm{~N}$ (as.) values $(256.6 \%$, $380.4 \%$ and $307.3 \%$, respectively). A closer look at these profiles (panel 17 on Fig. 2a) shows that the asymptotic $\delta^{15} \mathrm{~N}$ values are obtained following different trajectories with variations typically largest in the upper $10 \mathrm{~cm}$. These contrasting variations in $\delta^{15} \mathrm{~N}$ with depth have also been observed by Frey et al. (2009) using the DC04 and DC07-1 snow pits. The DC snow pit data reported in this study confirm this view. Frey et al. (2009) have attributed this feature to local surface heterogeneities linked to sastrugi formation and wind drift. We therefore propose that the high variability in $\delta^{15} \mathrm{~N}$ (as.) which can be observed at one individual site such as Vostok is the result of variability in local 
snow accumulation rates at the spatial scale of a few metres. This could explain the higher uncertainty observed in this study when constraining the Antarctic Plateau pits with the relationship found between $\ln \left(\delta^{15} \mathrm{~N}(\right.$ as. $\left.)+1\right)$ and $1 / A$ : $\ln \left(\delta^{15} \mathrm{~N}+1\right)=(4.22 \pm 1.43) \cdot\left(\mathrm{kg} \mathrm{m}^{-2} \mathrm{a}^{-1} / A\right)+(0.08 \pm 0.06)$.

\subsection{2 $\quad \Delta^{17} \mathrm{O}$ (as.) potential to trace changes in tropospheric oxidation}

We have shown that the temporal variations in $\Delta^{17} \mathrm{O}\left(\mathrm{NO}_{3}^{-}\right)$ in the snow skin layer at DC are correlated with those in the atmosphere due to the local recycling of nitrate initiated by the UV photolysis of snowpack nitrate in spring and summer. The difference between the two series decreases during spring and summer most likely because the nitrate reservoir in the skin layer is on average a factor 100 larger than the atmospheric pool, thus evolving with greater inertia. To investigate the transfer of the $\Delta^{17} \mathrm{O}$ atmospheric signal below the photic zone, we compare the $\Delta^{17} \mathrm{O}\left(\mathrm{NO}_{3}^{-}\right)$values in the two extreme compartments: the skin layer and the asymptotic nitrate (Fig. 8). The skin layer was not always sampled for the snow pits presented in this study; therefore, we use the samples representing the top $2 \mathrm{~cm}$ of snow, which are equivalent to those observed in Fig. 2b. Figure 8b shows the comparison between the $\Delta^{17} \mathrm{O}$ of nitrate in the top $2 \mathrm{~cm}$ of snow and the asymptotic $\Delta^{17} \mathrm{O}$ values obtained for each snow pit.

In the coastal zone, we note that $\Delta^{17} \mathrm{O}\left(\mathrm{NO}_{3}^{-}\right)$is preserved in the snow, as shown by the equivalent $\Delta^{17} \mathrm{O}\left(\mathrm{NO}_{3}^{-}\right)$ values in the top of the snowpack and below the active zone (Fig. 8b), consistent with small ${ }^{17} E_{\text {app values }((-0.2 \pm}$ 1.5) \%o on average). $\Delta^{17} \mathrm{O}\left(\mathrm{NO}_{3}^{-}\right)$for the top $2 \mathrm{~cm}$ of snow at sites close to D10 show values as high as $38 \%$ (Figs. 2b and $8 \mathrm{~b})$. A greater preservation of nitrate stratospheric inputs, or possibly nitrate formed through reactions involving halogens (e.g. bromine), must be invoked to explain such high values (Savarino et al., 2007; Morin et al., 2009; Frey et al., 2009).

On the plateau, $\Delta^{17} \mathrm{O}\left(\mathrm{NO}_{3}^{-}\right)$in the top $2 \mathrm{~cm}$ of snow is constant with an average $\Delta^{17} \mathrm{O}$ value of $30 \%$, in accordance with previous spatial collections of the upper $10 \mathrm{~cm}$ of snow conducted by Frey et al. (2009) in the same area. In this zone, $\Delta^{17} \mathrm{O}\left(\mathrm{NO}_{3}^{-}\right)$profiles show a significant decrease (between $5 \% o$ and $10 \%$ ) with depth, which erases the extremes observed in the atmospheric signal (Frey et al., 2009). For instance, $\Delta{ }^{17} \mathrm{O}$ is reduced from 29 to $22 \%$ in the top $50 \mathrm{~cm}$ of Site 15 (panel 15 on Fig. $2 b$ and Fig. $8 b$ ). The atmospheric $\Delta^{17} \mathrm{O}$ signal is therefore not entirely preserved during the transfer of nitrate from the surface to the snow below the photic zone (Fig. 8b). The observations for $\Delta^{17} \mathrm{O}$ are consistent with those for $\delta^{18} \mathrm{O}$ (Fig. 8c): asymptotic $\delta^{18} \mathrm{O}$ values are strongly reduced when compared to the rather constant $\delta^{18} \mathrm{O}$ values for nitrate in the top $2 \mathrm{~cm}$ of snow (around $40 \%$ on average). In addition, the positive ${ }^{17} E_{\text {app }}$ and ${ }^{18} \varepsilon_{\text {app }}$ values observed on the plateau, $(+2.0 \pm 1.0) \% o$ and $(+8.7 \pm 2.4) \%$ on average, reflect the observed reductions. We propose that the $\Delta^{17} \mathrm{O}$ reduction in Antarctic Plateau sites is the result of oxygen isotopic exchange and cage recombination effects during nitrate photolysis (McCabe et al., 2005; Frey et al., 2009), which has been shown here to characterize this area. At this stage, we cannot rule out the possibility that another process is responsible for the depletion of the ${ }^{18} \mathrm{O}$ isotopes in the nitrate remaining in the snow.

\section{Summary and conclusions}

The physical release of nitrate and its UV photolysis are associated with two distinct ${ }^{15} \mathrm{~N} /{ }^{14} \mathrm{~N}$ fractionation constants. While the two signatures of the loss processes are of the same sign, estimates of ${ }^{15} \varepsilon_{\text {phy }}$ show a value only slightly negative $((-3.6 \pm 1.1) \%)$, while the estimated value for ${ }^{15} \varepsilon_{\text {pho }}$ $(<-48 \%$, Frey et al., 2009) is more negative. Based on these two distinct isotopic signatures and on the ${ }^{15} \mathrm{~N} /{ }^{14} \mathrm{~N}$ apparent fractionation constants $\left({ }^{15} \varepsilon_{\text {app }}\right)$ derived from nitrate mass fraction and $\delta^{15} \mathrm{~N}$ measurements in snow pits, it is possible to determine the loss process which dominates nitrate mass loss at a given site. Nitrogen isotopic data from East Antarctic Plateau sites presented in this study show that nitrate UV photolysis is the dominant mass loss process in this area. In contrast, on the Antarctic coast, nitrate loss is less pronounced and could involve both photochemical and physical release processes. Apparent fractionation constants derived from the oxygen isotope ratios measured in nitrate $\left({ }^{17} E_{\text {app }}\right.$ and $\left.{ }^{18} \varepsilon_{\text {app }}\right)$ further support these conclusions with values non significantly different from zero and significantly positive at the coast and on the plateau, respectively. The latter reflects possible exchange of oxygen atoms between nitrate photoproducts and $\mathrm{H}_{2} \mathrm{O}$ in the snow grain lattice.

We recall that the ${ }^{15} \varepsilon_{\text {phy }}$ values obtained in this study must be considered with extreme care since the "physical release" experiment reported in this paper carries numerous caveats. Future laboratory experiment focusing on the determination of the isotopic fractionation constants associated with nitrate evaporation will need to better replicate field conditions. For instance, temperature gradients and wind pumping will need to be simulated and vapour pressures in the interstitial air will need to be controlled.

On the plateau, nitrate UV photolysis initiates a complex local recycling of nitrate. Annual nitrate collections in the atmosphere and skin layer (first mm of snow) at Dome C show an important consequence of this recycling: skin layer and atmospheric nitrates are in equilibrium in terms of oxygen isotope ratios but with a non-zero fractionation constant due

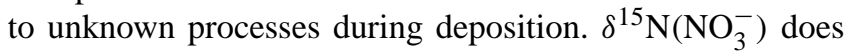
not follow the same trend and a constant shift of more than $24 \%$ is observed and has tentatively been attributed to an isotopic fractionation upon deposition. The deposition of nitrate from the atmosphere to the skin layer also explains the temporal offset of 3-4 weeks between the atmospheric and snow nitrate concentration time series. 


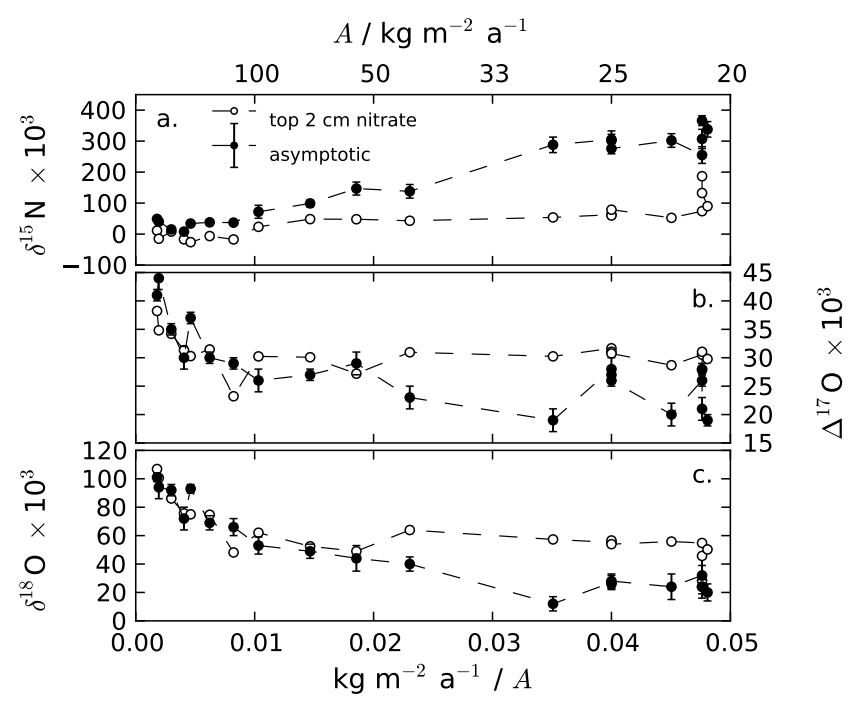

Fig. 8. Asymptotic nitrate isotopic composition and the isotopic composition of nitrate in the top $2 \mathrm{~cm}$ of snow in East Antarctica. (a) $\delta^{15} \mathrm{~N}\left(\mathrm{NO}_{3}^{-}\right)$, (b) $\Delta^{17} \mathrm{O}\left(\mathrm{NO}_{3}^{-}\right)$and (c) $\delta^{18} \mathrm{O}\left(\mathrm{NO}_{3}^{-}\right)$.

In this study we have calculated asymptotic values from the nitrate isotopic profiles obtained for each snow pit. In present-day snow on the Antarctic Plateau, asymptotic $\delta^{15} \mathrm{~N}$ values $\left(\delta^{15} \mathrm{~N}(\right.$ as. $\left.)\right)$ are the result of the highly negative ${ }^{15} \mathrm{~N} /{ }^{14} \mathrm{~N}$ fractionation constant set by nitrate UV photolysis (and imposed by the spetral distribution of the actinic flux, modulated by the ozone column above the plateau, Frey et al., 2009) and by the nitrate mass fractions lost by photolysis which are linked to the photolytic rate constant (Eq. 2). This rate constant is modulated not only by the UV intensity received at the snowpack surface but also by the quantum yield for photolysis $(\Phi)$ and by its residence time in snow layers in the photic zone. The correlation observed between $\delta^{15} \mathrm{~N}$ (as.) and $1 / A$ confirms the strong control of the snow accumulation rate on nitrate exposure time in the photic zone. A full discussion of this point is, however, beyond the scope of this paper but is considered in the companion paper (Erbland et al., 2013) We recall that the consistent shift (of the order of $25 \%$ ) observed between atmospheric and skin layer $\delta^{15} \mathrm{~N}\left(\mathrm{NO}_{3}^{-}\right)$time series at Dome $\mathrm{C}$ (Fig. 6c) is small when compared to the change of several hundreds of \%o imposed by nitrate UV photolysis, so this effect can be considered second order in the asymptotic $\delta^{15} \mathrm{~N}$ values.

On the plateau and during summer, $\Delta^{17} \mathrm{O}$ in skin layer nitrate is remarkably stable (around $30 \%$ ), and it may directly reflect the $\Delta^{17} \mathrm{O}$ in the atmospheric nitrate at each site and possibly the local oxidative state of the atmosphere. However, this study has confirmed the conclusions of Frey et al. (2009), who have shown a reduction of $\Delta^{17} \mathrm{O}\left(\mathrm{NO}_{3}^{-}\right)$at depth, possibly under the effect of oxygen isotopic exchange and cage recombination of the photoproducts. This reduction of $\Delta^{17} \mathrm{O}$, together with the important local recycling of ni- trate at the air-snow interface on the plateau complicates the extraction from $\Delta^{17} \mathrm{O}$ (as.) of information regarding the oxidative state of the atmosphere.

Because temperature gradients and wind pumping exist in the top metres of plateau snowpacks, nitrate could still be mobilized by physical processes, but any net loss is expected to be small compared to the intense loss through UV photolysis in the top decimetres. Furthermore, nitrate in ice can be considered as archived since it would diffuse from $3 \mathrm{~cm}$ to $14 \mathrm{~cm}$ over $100 \mathrm{kyr}$ and at temperatures ranging from $-50^{\circ} \mathrm{C}$ to $-20^{\circ} \mathrm{C}$ (Thibert and Domine, 1998). For the two reasons above, the isotopic composition of nitrate below the photic zone may well be archived and remain identical until nitrate is retrieved from ice cores and its isotope ratios are measured. Nitrate isotope ratios measured in ice (e.g. on the Antarctic plateau) could therefore record past changes in isotope ratios in nitrate escaping the photic zone, i.e. a few tens of $\mathrm{cm}$ below the surface. Obtaining a record of past changes in the isotopic composition of atmospheric nitrate (i.e. potential changes in the oxidative state of the atmosphere using $\Delta^{17} \mathrm{O}$ ) using isotope ratios measured in ice cores requires deconvolution of the integrated effects of nitrate recycling and oxygen isotopic exchange/cage recombination on nitrate isotope ratios measured in modern Antarctic Plateau snow pits.

Given the complexity of the processing undergone by nitrate at the air-snow interface in East Antarctica, a numerical model including the isotopic composition of nitrate is required to achieve this deconvolution. The companion paper (Erbland et al., 2013) presents an isotopic model relying on the conceptual model proposed by Davis et al. (2008) and Frey et al. (2009), which is tested by comparing its results with the atmospheric, skin layer and snow pit data obtained in the present study. This model could then be used in past conditions to provide a framework for the interpretation of deep ice core records in terms of past changes in the oxidative state of the atmosphere.

\section{Supplementary material related to this article is available online at: http://www.atmos-chem-phys.net/13/ 6403/2013/acp-13-6403-2013-supplement.pdf.}

Acknowledgements. We thank A. Maggi, J.-Y. Thore (Université de Strasbourg, France) and K. Agabi (Université Nice Sophia Antipolis, France) as well as the winterover crews of the Concordia (Dome C) base for their help with the snow sampling in the field. The French Polar Institute (IPEV) is thanked for its logistical support in Antarctica. V. Lipenkov (AARI, St Petersburg, Russia) is thanked for providing the V09-1 and V09-2 snow pits from Vostok. We thank G. Krinner for downloading the ERA-Interim temperature data, G. Picard for processing them and G. Krinner and S. Parouty for providing the snow accumulation data. The Agence Nationale de la Recherche (ANR) is gratefully acknowledged for its financial support through the VANISH (contract ANR-07-VULN-013) and 
OPALE (contract ANR-09-BLAN-0226) projects. This study has also benefited partial funding from LICENCE (LEFE-CHAT), a scientific programme of the Institut National des Sciences de l'Univers (INSU/CNRS), as well as from the IPICS programme (CNRS) and from IPEV (programme NITEDC - 1011). We thank B. Alexander, one anonymous reviewer and the Hastings' lab group for useful comments and suggestions during the review process. This study would not have been possible without the courage and experience of the Antarctic pilots flying over Antarctica. We remember our colleague, Bob Heath, and his crew, who devoted their life to Antarctic research.

Edited by: J. Kaiser

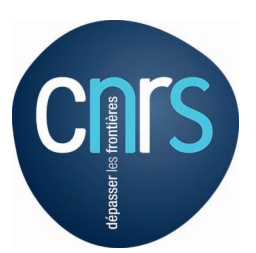

The publication of this article is financed by CNRS-INSU.

\section{References}

Alexander, B., Savarino, J., Kreutz, K. J., and Thiemens, M. H.: Impact of preindustrial biomass-burning emissions on the oxidation pathways of tropospheric sulfur and nitrogen, J. Geophys. Res., 109, D08303, doi:10.1029/2003JD004218, 2004.

Alexander, B., Hastings, M. G., Allman, D. J., Dachs, J., Thornton, J. A., and Kunasek, S. A.: Quantifying atmospheric nitrate formation pathways based on a global model of the oxygen isotopic composition $\left(\Delta^{17} \mathrm{O}\right)$ of atmospheric nitrate, Atmos. Chem. Phys., 9, 5043-5056, doi:10.5194/acp-9-5043-2009, 2009.

Blunier, T., Floch, G. L., Jacobi, H.-W., and Quansah, E.: Isotopic view on nitrate loss in Antarctic surface snow, Geophys. Res. Lett., 32, L13501, doi:10.1029/2005GL023011, 2005.

Casciotti, K. L., Sigman, D. M., Hastings, M. G., Böhlke, J. K., and Hilkert, A.: Measurement of the oxygen isotopic composition of nitrate in seawater and freshwater using the denitrifier method, Anal. Chem., 74, 4905-4912, doi:10.1021/ac020113w, 2002.

Chu, L. and Anastasio, C.: Quantum yields of hydroxyl radical and nitrogen dioxide from the photolysis of nitrate on ice, J. Phys. Chem., 107, 9594-9602, 2003.

Criss, R. E.: Principles of stable isotope distribution, Oxford University Press, New York, 1999.

Davis, D. D., Seelig, J., Huey, G., Crawford, J., Chen, G., Wang, Y., Buhr, M., Helmig, D., Neff, W., Arimoto, D. B. R., and Eisele, F.: A reassessment of Antarctic plateau reactive nitrogen based on ANTCI 2003 airborne and ground based measurements, Atmos. Environ., 42, 2831-2848, doi:10.1016/j.atmosenv.2007.07.039, 2008.

Dee, D. P., Uppala, S. M., Simmons, A. J., Berrisford, P., Poli, P., Kobayashi, S., Andrae, U., Balmaseda, M. A., Balsamo, G., Bauer, P., Bechtold, P., Beljaars, A. C. M., van de Berg, L., Bidlot, J., Bormann, N., Delsol, C., Dragani, R., Fuentes, M., Geer, A. J., Haimberger, L., Healy, S. B., Hersbach, H., Hólm, E. V., Isaksen, L., Kållberg, P., Köhler, M., Matricardi, M., McNally, A. P., Monge-Sanz, B. M., Morcrette, J.-J., Park, B.-K., Peubey, C., de Rosnay, P., Tavolato, C., Thépaut, J.-N., and Vitart, F.: The ERA-Interim reanalysis: configuration and performance of the data assimilation system, Q. J. Roy. Meteorol. Soc., 137, 553597, doi:10.1002/qj.828, 2011.

Dibb, J. E., Talbot, R. W., Munger, J. W., Jacob, D. J., and Fan, S. M.: Air-snow exchange of $\mathrm{HNO}_{3}$ and $\mathrm{NO}_{y}$ at Summit, Greenland, J. Geophys. Res., 103, 3475-3486, doi:10.1029/97JD03132, 1998.

Domine, F., Albert, M., Huthwelker, T., Jacobi, H.-W., Kokhanovsky, A. A., Lehning, M., Picard, G., and Simpson, W. R.: Snow physics as relevant to snow photochemistry, Atmos. Chem. Phys., 8, 171-208, doi:10.5194/acp-8-171-2008, 2008.

Ekaykin, A. A., Lipenkov, V. Y., Barkov, N., Petit, J.-R., and Masson-Delmotte, V.: Spatial and temporal variability in isotope composition of recent snow in the vicinity of Vostok station, Antarctica: implications for ice-core record interpretation, Ann. Glaciol., 35, 181-186, doi:10.3189/172756402781816726, 2002.

EPICA community members: Eight glacial cycles from an Antarctic ice core, Nature, 429, 623-628, doi:10.1038/nature02599, 2004.

Erbland, J., Savarino, J., Morin, S., France, J. L., and Frey, M. M.: Air-snow transfer of nitrate on the East Antarctic plateau - Part 2: An isotopic model for the interpretation of deep ice-core records, Atmos. Chem. Phys. Discuss., in preparation, 2013.

France, J. L., King, M. D., Frey, M. M., Erbland, J., Picard, G., Preunkert, S., MacArthur, A., and Savarino, J.: Snow optical properties at Dome C (Concordia), Antarctica; implications for snow emissions and snow chemistry of reactive nitrogen, Atmos. Chem. Phys., 11, 9787-9801, doi:10.5194/acp-11-97872011, 2011.

Frey, M. M., Savarino, J., Morin, S., Erbland, J., and Martins, J. M. F.: Photolysis imprint in the nitrate stable isotope signal in snow and atmosphere of East Antarctica and implications for reactive nitrogen cycling, Atmos. Chem. Phys., 9, 8681-8696, doi:10.5194/acp-9-8681-2009, 2009.

Freyer, H. D., Kobel, K., Delmas, R. J., Kley, D., and Legrand, M. R.: First results of ${ }^{15} \mathrm{~N} /{ }^{14} \mathrm{~N}$ ratios in nitrate from alpine and polar ice cores, Tellus, 48B, 93-105, 1996.

Gallet, J.-C., Domine, F., Arnaud, L., Picard, G., and Savarino, J.: Vertical profile of the specific surface area and density of the snow at Dome C and on a transect to Dumont D'Urville, Antarctica - albedo calculations and comparison to remote sensing products, The Cryosphere, 5, 631-649, doi:10.5194/tc-5-6312011, 2011.

Grannas, A. M., Jones, A. E., Dibb, J., Ammann, M., Anastasio, C., Beine, H. J., Bergin, M., Bottenheim, J., Boxe, C. S., Carver, G., Chen, G., Crawford, J. H., Dominé, F., Frey, M. M., Guzmán, M. I., Heard, D. E., Helmig, D., Hoffmann, M. R., Honrath, R. E., Huey, L. G., Hutterli, M., Jacobi, H. W., Klán, P., Lefer, B., McConnell, J., Plane, J., Sander, R., Savarino, J., Shepson, P. B., Simpson, W. R., Sodeau, J. R., von Glasow, R., Weller, R., Wolff, E. W., and Zhu, T.: An overview of snow photochemistry: evidence, mechanisms and impacts, Atmos. Chem. Phys., 7, 43294373, doi:10.5194/acp-7-4329-2007, 2007.

Huey, L. G., Tanner, D. J., Slusher, D. L., Dibb, J. E., Arimoto, R., Chen, G., Davis, D., Buhr, M. P., Nowak, J. B., Mauldin III, R. L., Eisele, F. L., and Kosciuch, E.: CIMS measurements of $\mathrm{HNO}_{3}$ and $\mathrm{SO}_{2}$ at the South Pole during ICAT 2000, Atmos. Environ., 38, 5411-5421, doi:10.1016/j.atmosenv.2004.04.037, 2004. 
Kaiser, J., Hastings, M. G., Houlton, B. Z., Röckmann, T., and Sigman, D. M.: Triple oxygen isotope analysis of nitrate using the denitrifier method and thermal decomposition of $\mathrm{N}_{2} \mathrm{O}$, Anal. Chem., 79, 599-607, doi:10.1021/ac061022s, 2007.

Krinner, G., Magand, O., Simmonds, I., Genthon, C., and Dufresne, J.: Simulated Antarctic precipitation and surface mass balance at the end of the twentieth and twenty-first centuries, Clim. Dynam., 28, 215-230, doi:10.1007/s00382-006-0177-x, 2007.

Kunasek, S. A., Alexander, B., Steig, E. J., Hastings, M. G., Gleason, D. J., and Jarvis, J. C.: Measurements and modeling of $\Delta^{17} \mathrm{O}$ of nitrate in snowpits from Summit, Greenland, J. Geophys. Res., 113, D24302, doi:10.1029/2008JD010103, 2008.

Legrand, M., Gros, V., Preunkert, S., Sarda-Estève, R., Thierry, A.-M., Pépy, G., and Jourdain, B.: A reassessment of the budget of formic and acetic acids in the boundary layer at Dumont d'Urville (coastal Antarctica): The role of penguin emissions on the budget of several oxygenated volatile organic compounds, J. Geophys. Res., 117, D06308, doi:10.1029/2011JD017102, 2012.

Mayewski, P. A. and Legrand, M. R.: Recent Increase in Nitrate Concentration of Antarctic Snow, Nature, 346, 258-260, 1990.

McCabe, J. R., Boxe, C. S., Colussi, A. J., Hoffman, M. R., and Thiemens, M. H.: Oxygen isotopic fractionation in the photochemistry of nitrate in water and ice, J. Geophys. Res., 110 (D15310), doi:10.1029/2004JD005484, 2005.

McCabe, J. R., Savarino, J., Alexander, B., Gong, S., and Thiemens, M. H.: Isotopic constraints on non-photochemical sulfate production in the Arctic winter, Geophys. Res. Lett., 33, L05810, doi:10.1029/2005GL025164, 2006.

McCabe, J. R., Thiemens, M. H., and Savarino, J.: A record of ozone variability in South Pole Antarctic snow: The role of nitrate oxygen isotopes, J. Geophys. Res., 112, D12303, doi:10.1029/2006JD007822, 2007.

Michalski, G., Scott, Z., Kabiling, M., and Thiemens, M. H.: First measurements and modeling of $\Delta{ }^{17} \mathrm{O}$ in atmospheric nitrate, Geophys. Res. Lett., 30, 1870, doi:10.1029/2003GL017015, 2003.

Miller, C. E. and Yung, Y. L.: Photo-induced isotopic fractionation, J. Geophys. Res., 105, 29039-29051, 2000.

Morin, S., Savarino, J., Frey, M. M., Yan, N., Bekki, S., Bottenheim, J. W., and Martins, J. M. F.: Tracing the origin and fate of $\mathrm{NO}_{x}$ in the Arctic atmosphere using stable isotopes in nitrate, Science, 322, 730-732, doi:10.1126/science.1161910, 2008.

Morin, S., Savarino, J., Frey, M. M., Domine, F., Jacobi, H. W., Kaleschke, L., and Martins, J. M. F.: Comprehensive isotopic composition of atmospheric nitrate in the Atlantic Ocean boundary layer from $65^{\circ} \mathrm{S}$ to $79^{\circ} \mathrm{N}, \mathrm{J}$. Geophys. Res., 114, D05303, doi:10.1029/2008JD010696, 2009.

Morin, S., Sander, R., and Savarino, J.: Simulation of the diurnal variations of the oxygen isotope anomaly $\left(\Delta^{17} \mathrm{O}\right)$ of reactive atmospheric species, Atmos. Chem. Phys., 11, 3653-3671, doi:10.5194/acp-11-3653-2011, 2011.

Neubauer, J. and Heumann, K. G.: Determination of nitrate at the $\mathrm{ng} / \mathrm{g}$ level in Antarctic snow samples with ion chromatography and isotope-dilution mass-spectrometry, Fresenius J. Anal. Chem., 331, 170-173, 1988.
Pinzer, B. R., Schneebeli, M., and Kaempfer, T. U.: Vapor flux and recrystallization during dry snow metamorphism under a steady temperature gradient as observed by time-lapse microtomography, The Cryosphere, 6, 1141-1155, doi:10.5194/tc-61141-2012, 2012.

Röthlisberger, R., Hutterli, M. A., Sommer, S., Wolff, E. W., and Mulvaney, R.: Factors controlling nitrate in ice-cores : evidence from the Dome C deep ice core, J. Geophys. Res., 105, 2056520572, 2000.

Röthlisberger, R., Hutterli, M. A., Wolff, E. W., Mulvaney, P., Fischer, H., Bigler, M., Goto-Azuma, K., Hansson, M. E., Ruth, U., Siggaard-Andersen, M.-L., and Steffensen, J. P.: Nitrate in Greenland and Antarctic ice cores: a detailed description of postdepositional processes, Ann. Glaciol., 35, 209-216, 2002.

Röthlisberger, R., Mulvaney, R., Wolff, E. W., Hutterli, M. A., Bigler, M., De Angelis, M., Hansson, M. E., Steffensen, J. P., and Udisti, R.: Limited dechlorination of sea-salt aerosols during the last glacial period : Evidence from the European Project for Ice Coring in Antarctica (EPICA) Dome C ice core, J. Geophys. Res., 108, D16 (4526), doi:10.1029/2003JD003604, 2003.

Savarino, J., Kaiser, J., Morin, S., Sigman, D. M., and Thiemens, M. H.: Nitrogen and oxygen isotopic constraints on the origin of atmospheric nitrate in coastal Antarctica, Atmos. Chem. Phys., 7, 1925-1945, doi:10.5194/acp-7-1925-2007, 2007.

Sigman, D. M., Casciotti, K. L., Andreani, M., Barford, C., Galanter, M., and Böhlke, J. K.: A bacterial method for the nitrogen isotopic analysis of nitrate in marine and fresh waters, Anal. Chem., 73, 4145-4153, 2001.

Silva, S. R., Kendall, C., Wilkinson, D. H., Ziegler, A. C., Chang, C. C. Y., and Avanzino, R. J.: A new method for collection of nitrate from fresh water and analysis of the nitrogen and oxygen isotope ratios, J. Hydrol., 228, 22-36, 2000.

Simpson, W. R., King, M. D., Beine, H. J., Honrath, R. E., and Zhou, X.: Radiation-transfer modeling of snow pack photochemical processes during ALERT2000, Atmos. Environ., 36, 26632670, 2002.

Taylor, J. R.: An Introduction to Error Analysis: The study of uncertainties in physical measurements, University Science Books, 2 Edn., 1997.

Thibert, E. and Domine, F.: Thermodynamics and kinetics of the solid solution of $\mathrm{HNO}_{3}$ in ice, J. Phys. Chem. B, 102, 44324439, 1998.

Wolff, E.: Ice core studies of global biogeochemical cycles, chap. Nitrate in polar ice, 195-224, Springer-Verlag, New York, 1995.

Wolff, E. W., Jones, A. E., Bauguitte, S. J.-B., and Salmon, R. A.: The interpretation of spikes and trends in concentration of nitrate in polar ice cores, based on evidence from snow and atmospheric measurements, Atmos. Chem. Phys., 8, 5627-5634, doi:10.5194/acp-8-5627-2008, 2008.

Zatko, M. C., Grenfell, T. C., Alexander, B., Doherty, S. J., Thomas, J. L., and Yang, X.: The influence of snow grain size and impurities on the vertical profiles of actinic flux and associated $\mathrm{NO}_{\mathrm{x}}$ emissions on the Antarctic and Greenland ice sheets, Atmos. Chem. Phys., 13, 3547-3567, doi:10.5194/acp-13-35472013, 2013. 